\title{
Steroid Treatment in Macular Edema: A Bibliometric Study and Visualization Analysis
}

\author{
Yu Lin ${ }^{1,2 \dagger}$, Xiang Ren ${ }^{1,2 \dagger}$ and Danian Chen ${ }^{1,2 *}$ \\ ${ }^{1}$ Research Laboratory of Ophthalmology and Vision Sciences, State Key Laboratory of Biotherapy, West China Hospital, Sichuan \\ University, Chengdu, China, ${ }^{2}$ Department of Ophthalmology, West China Hospital, Sichuan University, Chengdu, China
}

The use of steroids to treat macular edema (ME) is a research hotspot in ophthalmology. We utilized CiteSpace and VOSviewer software to evaluate the Web of Science Core Collection publications and to build visualizing maps to describe the research progress in this topic. There were 3,252 publications for three decades during 1988-2021. The number of studies was low during the first 14 years but has risen consistently in the following two decades. The average publications per year were only 4.8 during 1988-2002, which jumped to 113 per year during 2003-2012, and 227 per year during 2013-2021. These publications came from 83 countries/regions, with the

OPEN ACCESS

Edited by: Settimio Rossi,

Second University of Naples, Italy

Reviewed by: Giovanni Luca Romano, University of Catania, Italy Ehab Ghoneim,

Portsaid University, Egypt

*Correspondence: Danian Chen danianchen2006@qq.com

${ }^{t}$ These authors have contributed equally to this work

Specialty section: This article was submitted to Inflammation Pharmacology, a section of the journal Frontiers in Pharmacology

Received: 29 November 2021 Accepted: 17 January 2022

Published: 22 February 2022

Citation:

Lin Y, Ren X and Chen D (2022) Steroid Treatment in Macular Edema: A Bibliometric Study and Visualization Analysis. Front. Pharmacol. 13:824790. doi: 10.3389/fphar.2022.824790 United States, Germany, and Italy leading positions. Most studies were published in Investigative Ophthalmology Visual Science, and Ophthalmology was the most cited journal. We found 9,993 authors, with Bandello F having the most publications and Jonas JB being the most frequently co-cited. According to our research, the most popular keyword is triamcinolone acetonide (TA). Macular edema, diabetic macular edema (DME), retinal vein occlusion (RVO), dexamethasone (DEX), fluocinolone acetonide (FA), and some other keywords were commonly studied in this field. In conclusion, the bibliometric analysis provides a comprehensive overview of steroid hotspots and developmental tendencies in the macular edema study. While anti-VEGF therapy is the first-line treatment for DME and RVO-induced macular edema, steroids implant is a valid option for these DME patients not responding to anti-VEGF therapy and non-DME patients with macular edema. Combined therapy with anti-VEGF and steroid agents is vital for future research.

Keywords: steroids, macular edema, intravitreal injection, citespace, VOSviewer, bibliometric study

\section{INTRODUCTION}

The macula is responsible for central vision and locates at the center of retina, temporal to the optic nerve head (Daruich et al., 2018). Macular diseases can cause blurred vision, distorted vision, and vision loss (Chung, 2020). Macular edema (ME) develops when fluid accumulates in the macular layers due to vascular leakage, causing the macula to swell and thicken, distorting vision (Lang, 2012). It is a complication of several retinal disorders and other diseases, including diabetic retinopathy (DR), agerelated macular degeneration (AMD), retinal vein occlusion (RVO), and inflammatory diseases (such as uveitis and retinal necrosis) (Welfer et al., 2011; Smith and Kaiser, 2014; Aksu-Ceylan et al., 2021; Hykin et al., 2021; Tappeiner et al., 2021). The most common causes of macular edema are DR and RVO (Daruich et al., 2018). It affects about 7 million DR patients (Yau et al., 2012), 3 million RVO patients (Rogers et al., 2010), and 40\% of uveitis patients (Rothova et al., 1996; Karim et al., 2013). 
Several approaches have been developed to treat macular edema and its underlying causes, such as anti-vascular endothelial growth factor (anti-VEGF) therapies, anti-inflammatory treatments, focal laser photocoagulation, carbonic anhydrase inhibitors, and vitrectomy (Mahdy et al., 2010; Supuran, 2019; Shimura et al., 2020; Aref et al., 2021; Mohan et al., 2021). Grid and focal laser photocoagulation, which was once the standard treatment for macular edema, is declining (Romero-Aroca, 2015). On the other hand, intravitreal injections have been commonly utilized to treat macular edema recently (Romero-Aroca, 2015). Anti-VEGF agents and corticosteroids are the most commonly administered drugs intravitreally (Distefano et al., 2017). Anti-VEGF agents can reduce vascular permeability and leakage (Simó et al., 2014). Antiinflammatory steroids could help repair the blood-retinal barrier and decrease exudation (Cunningham et al., 2008; Sarao et al., 2014). Triamcinolone acetonide (TA), dexamethasone (DEX), and fluocinolone acetonide (FA) are the three most often utilized steroids in the treatment of vitreoretinal disorders (Whitcup et al., 2018). The first steroid to treat AMD and macular edema was TA, which was followed by DEX and FA (Bandello et al., 2014).

Recently sustained-release devices have been developed and approved for intravitreal steroid administration, such as an intravitreal implant that can sustain drug delivery of DEX for up to 6 months (Bucolo et al., 2018). When macular edema is caused by vitreous traction, vitrectomy can relieve the tractional forces pulling on the macula (Yoshizumi et al., 2019). Other new therapeutic agents, such as minocycline and integrin antagonists, are being examined in clinical trials to reverse or even prevent the development of macular edema (Cukras et al., 2012; Shaw et al., 2020).

Bibliometric analysis, which focuses on the literature systems and characteristics, investigates hotspots and developmental trends in the scientific literature, using qualitative and quantitative analysis to describe the relationships between citing and co-cited references and depict the contributions of various authors, countries, and journals (Gu et al., 2021; Ma et al., 2021). This approach can help develop guidelines, identify research hotspots, and predict research trends (Guler et al., 2016). As previously stated, there are many therapeutic options for treating macular edema. New progress has recently been achieved in the study of steroids, particularly in the drug delivery system of these medicines. Thus, we want to use bibliometric analysis software to map out hotspots and developmental trends in using steroids to treat macular edema over the last three decades.

\section{METHODS}

\subsection{Data Collection and Search Strategies}

We searched the Web of Science (WOS) Core Collection database for all literature on the treatment of macular edema with steroids. All searches were performed on a single day, 7 October 2021, to avoid biases introduced by daily database updating. The search strategies were integrated as follows: $\mathrm{TI}=$ (macular edema) AND $\mathrm{TS}=$ (glucocorticoid OR steroid OR dexamethasone OR fluortriamcinolone acetonide OR triamcinolone acetonide). A total of 3,252 records from 1988 to 2021 were identified from WOS. In the WOS citation report, these entries were cited 67,645 times in total. In the following analysis, we used all these 3,252 records, including 2,348 articles, 402 reviews, 295 meeting abstracts, 122 letters, 68 editorial materials, 8 proceedings papers, 8 corrections, and 1 item of news. The retrieved eligible publications were exported and saved as plain text files, including titles, keywords, publication dates, countries and regions, institutions, authors, publishing journals, and sums of citations (Figure 1).

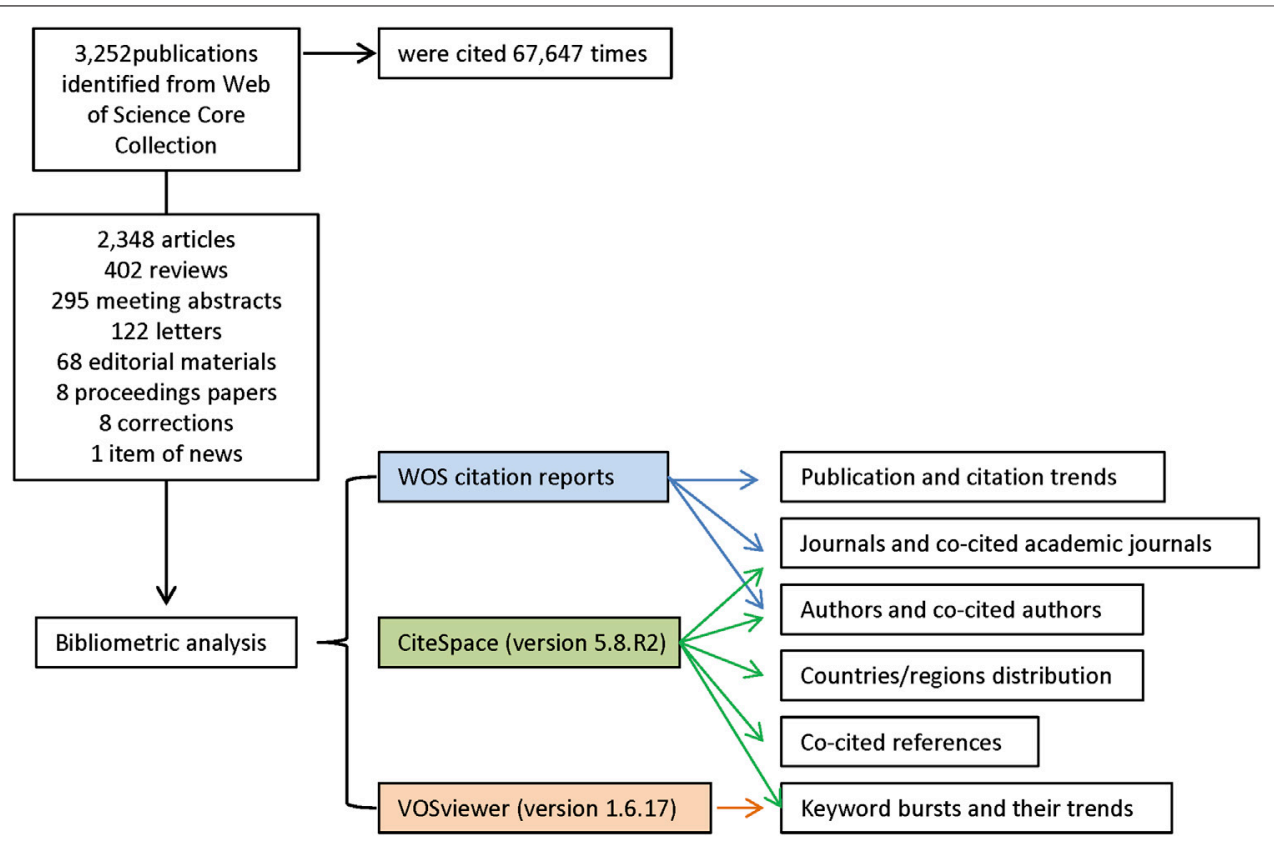

FIGURE 1 | Flow diagram of the included publications and methods of bibliometric analysis. 
A

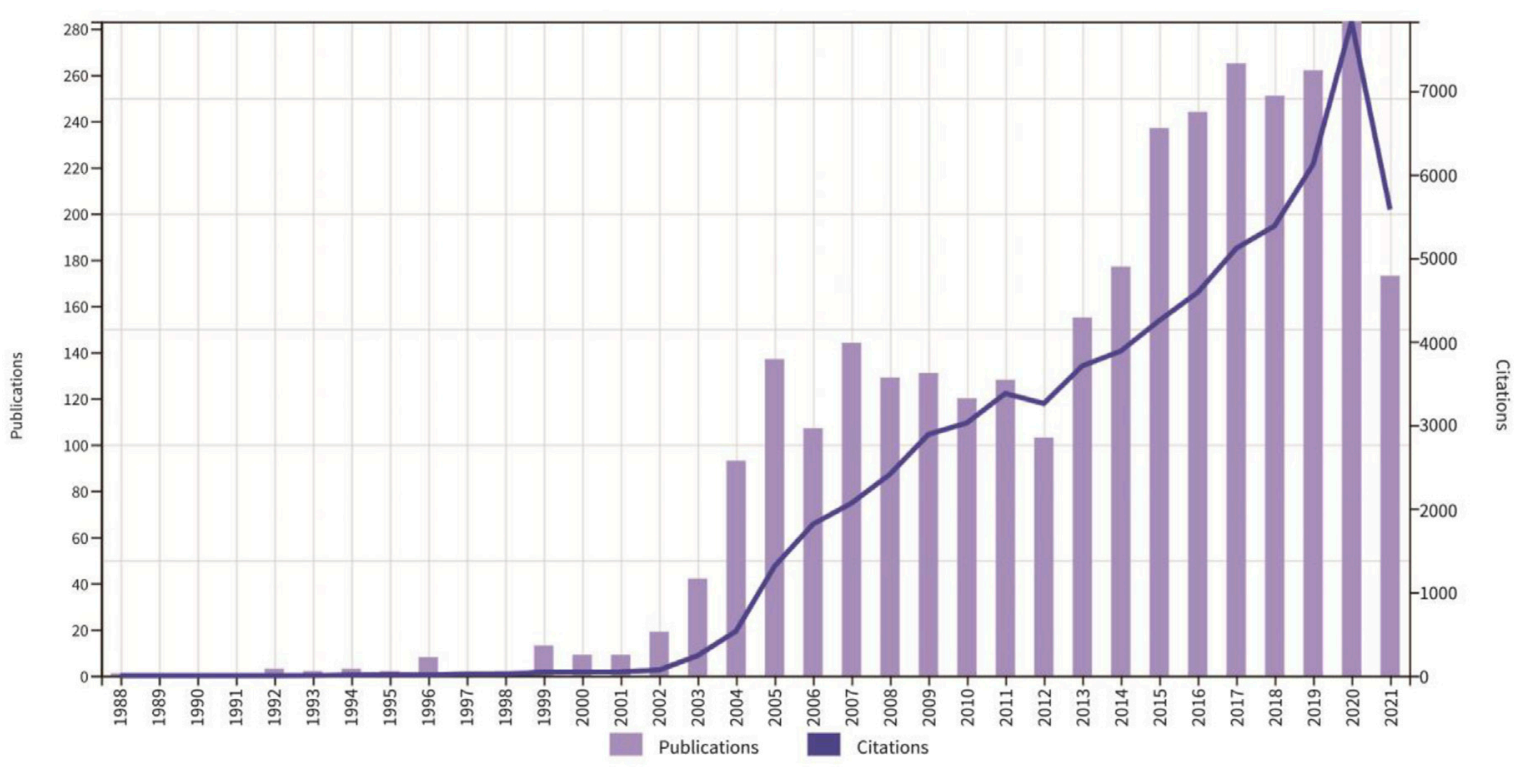

B

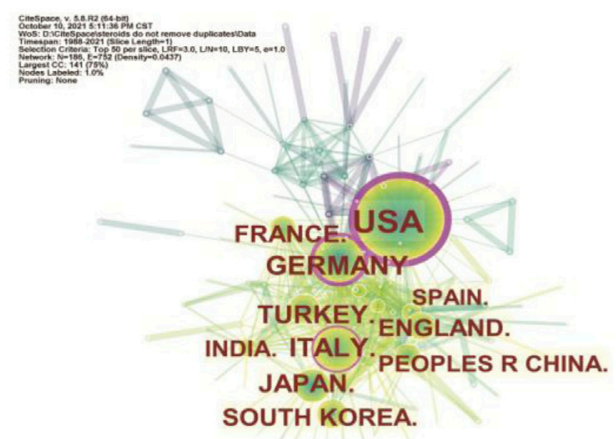

C

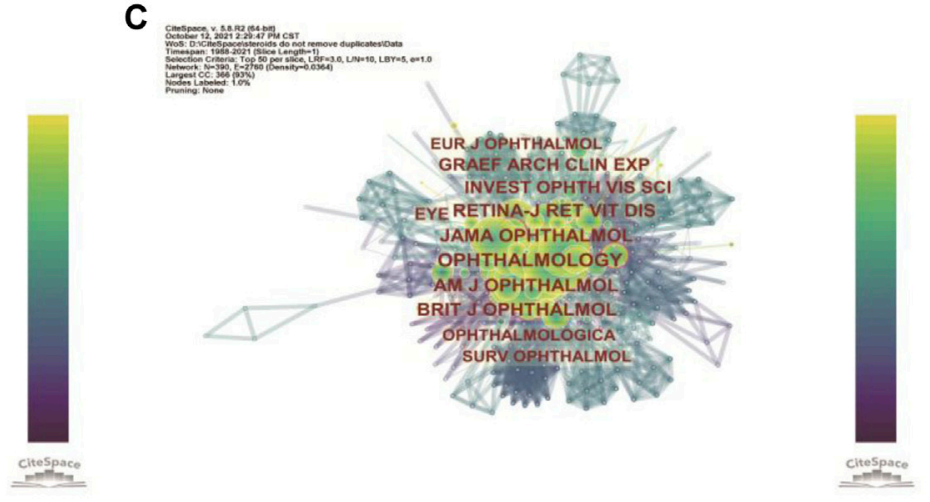

D

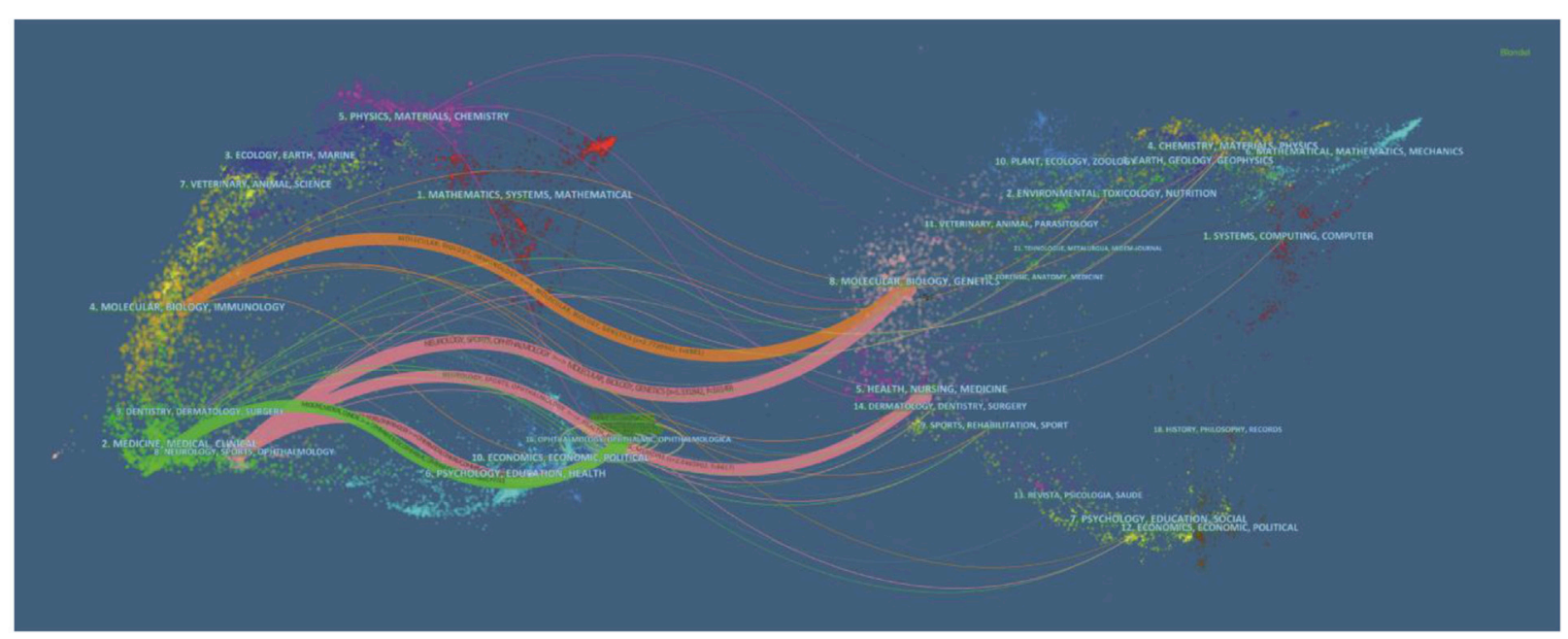

FIGURE 2 | Distribution of publications and citations from different years, countries and journals. (A) The distribution of the bibliographic records in Set \#7 (Table 1), showing the number of publications and citations during different years. (B) Distributions of publications from different countries. (C) CiteSpace visualization map of cocited journals. (D) The dual-map overlay of journals. The dual-map shows the relationships between publications and citations, with dots representing citing journals on the left and cited journals on the right. 
TABLE 1 | Distribution of publications from different countries/regions.

\begin{tabular}{llc}
\hline No. & \multicolumn{1}{c}{ Country } & Counts (\%) \\
\hline 1 & United States & $913(28.066 \%)$ \\
2 & Germany & $321(9.868 \%)$ \\
3 & Italy & $314(9.653 \%)$ \\
4 & Turkey & $242(7.439 \%)$ \\
5 & England & $209(6.425 \%)$ \\
6 & France & $204(6.271 \%)$ \\
7 & Japan & $203(6.240 \%)$ \\
8 & South Korea & $179(5.503 \%)$ \\
9 & India & $153(4.703 \%)$ \\
10 & Peoples R China & $146(4.488 \%)$
\end{tabular}

\subsection{Bibliometric Analyzing}

The exported data were imported into CiteSpace version 5.8.R2 (Drexel University, Philadelphia, United States) (Chen et al., 2012; Chen, 2017) and VOSviewer version 1.6.17 (Leiden University, Leiden, Netherlands) (van Eck and Waltman, 2010) and analyzed both quantitatively and qualitatively. We used the "eliminating duplicates function" in CiteSpace to perform simple literature curation before doing the co-word analysis and document co-citation analysis. Thus the final dataset included no duplicates. The publication and citation trends were generated from the citation reports of WOS. CiteSpace was used to identify countries/regions distribution, journals and co-cited academic journals, authors and co-cited authors, keyword bursts and their trends, and co-cited references. VOSviewer was employed to map and visualize the network of hotspots (keywords) related to macular edema treated with steroids research. Hotspots were classified into disparate clusters according to co-occurrence analysis and simultaneously color-coded by time course. Detailed procedures of the enrolment and analysis are illustrated in Figure 1.

\section{RESULTS}

\subsection{The Publication and Citation Trends}

The number of publications and citations in a research field shows the evolution of research. The number of publications related to the treatment of macular edema with steroids by year was presented in Figure 2A. While there were less than 5 publications per year during 1988-2002, the number of publications increased to about 110 publications per year on average during 2003-2012. The number of publications increased dramatically to about 230 publications per year on average during 2013-2021 (Figure 2A). For instance, in 2020 , the total number of outputs reached 283, and the number of citations increased to 7,829 , which both achieved the climax (Figure 2A). In total, 3,252 publications have been cited 67,645 times, and the average number of citations per publication is 20.8 times. Likely, the citation frequency of these studies increased steadily from 1988 to 2021 (Figure 2A). These data indicated that the steroids agent is more and more commonly used to treat macular edema.

\subsection{Analysis of Leading Countries/Region}

These studies were published by researchers in 83 countries and regions worldwide. The top 10 countries/regions contributing to this research field were mainly America, Europe, and Asia (Table 1). More than one-quarter of the publications were from the United States (913, 28.066\%). Germany (321, $9.868 \%)$, Italy $(314,9.653 \%)$, Turkey $(242,7.439 \%)$, and England $(209,6.425 \%)$ also made significant contributions to this topic (Table 1). The United States is the largest node on the country network map (Figure 2B). In addition, certain countries, such as the United States, Germany, and Italy, showed high centrality and were circled in the purple ring, implying that these countries may have played a crucial role in this research field (Figure 2B).

\begin{tabular}{|c|c|c|c|c|c|c|}
\hline No. & Journal & Count (\%) & $\begin{array}{c}\text { JCR } \\
(2020)\end{array}$ & Co-cited Journal & $\begin{array}{l}\text { Citation } \\
\text { count }\end{array}$ & $\begin{array}{c}\text { JCR } \\
(2020)\end{array}$ \\
\hline 1 & Investigative Ophthalmology Visual Science & $\begin{array}{c}306 \\
(9.407 \%)\end{array}$ & Q1 & Ophthalmology & 2645 & Q1 \\
\hline 2 & $\begin{array}{l}\text { Retina - The Journal of Retinal and Vitreous } \\
\text { Diseases }\end{array}$ & $\begin{array}{c}247 \\
(7.593 \%)\end{array}$ & Q1 & American Journal of Ophthalmology & 2327 & Q1 \\
\hline 3 & European Journal of Ophthalmology & $\begin{array}{c}146 \\
(4.488 \%)\end{array}$ & Q3 & $\begin{array}{l}\text { JAMA Ophthalmology (formerly Archives of } \\
\text { Ophthalmology) }\end{array}$ & 2249 & Q1 \\
\hline 4 & American Journal of Ophthalmology & $\begin{array}{c}136 \\
(4.181 \%)\end{array}$ & Q1 & $\begin{array}{l}\text { Retina - The Journal of Retinal and Vitreous } \\
\text { Diseases }\end{array}$ & 2044 & Q1 \\
\hline 5 & $\begin{array}{l}\text { Graefes Archive for Clinical and Experimental } \\
\text { Ophthalmology }\end{array}$ & $\begin{array}{c}123 \\
(3.781 \%)\end{array}$ & Q2 & British Journal of Ophthalmology & 1858 & Q1 \\
\hline 6 & Ophthalmology & $\begin{array}{c}120 \\
(3.689 \%)\end{array}$ & Q1 & Investigative Ophthalmology Visual Science & 1543 & Q1 \\
\hline 7 & Journal of Ocular Pharmacology and Therapeutics & $99(3.043 \%)$ & Q2 & $\begin{array}{l}\text { Graefes Archive for Clinical and Experimental } \\
\text { Ophthalmology }\end{array}$ & 1402 & Q2 \\
\hline 8 & Ophthalmologica & $94(2.890 \%)$ & Q2 & Eye & 1254 & Q1 \\
\hline
\end{tabular}

Q1: Quartile 1 of JCR 2020. 
TABLE 3 | Top 10 authors and co-cited authors.

\begin{tabular}{|c|c|c|c|c|c|c|}
\hline No. & Author & Country & Count (\%) & Co-cited author & Country & Citation count \\
\hline 1 & Bandello F & Italy & 77 (2.367\%) & Jonas JB & Germany & 902 \\
\hline 2 & Jonas JB & Germany & 57 (1.752\%) & Haller JA & United States & 597 \\
\hline 3 & Loewenstein A & Israel & 49 (1.506\%) & Campochiaro PA & United States & 542 \\
\hline 4 & Scott IU & United States & 38 (1.168\%) & Gillies MC & Australia & 516 \\
\hline 5 & Whitcup SM & United States & 34 (1.045\%) & Ip MS & United States & 487 \\
\hline 6 & Gillies MC & Australia & 33 (1.014\%) & Boyer DS & United States & 476 \\
\hline 7 & Kodjikian L & France & 33 (1.014\%) & Martidis A & United States & 395 \\
\hline 8 & Kuppermann BD & United States & $31(0.953 \%)$ & Massin $\mathrm{P}$ & France & 377 \\
\hline 9 & Kreissig I & Germany & $29(0.891 \%)$ & Klein R & United States & 370 \\
\hline 10 & Sakamoto T & Japan & $29(0.891 \%)$ & Brown DM & United States & 337 \\
\hline
\end{tabular}

\section{TABLE 4 | Top 30 keywords.}

\begin{tabular}{llc} 
No. & \multicolumn{1}{c}{ Keywords } & Count \\
\hline 1 & Triamcinolone acetonide & 1284 \\
2 & Injection & 526 \\
3 & Bevacizumab & 495 \\
4 & Macular edema & 444 \\
5 & Endothelial growth factor & 425 \\
6 & Ranibizumab & 331 \\
7 & Retinopathy & 317 \\
8 & Diabetic macular edema & 272 \\
9 & Efficacy & 265 \\
10 & Cystoid macular edema & 262 \\
11 & Retinal vein occlusion & 243 \\
12 & Optical coherence tomography & 235 \\
13 & Safety & 227 \\
14 & Therapy & 197 \\
15 & Trial & 195 \\
16 & Eye & 185 \\
17 & Visual acuity & 167 \\
18 & Drug delivery system & 167 \\
19 & Intraocular pressure & 165 \\
20 & Management & 163 \\
21 & Degeneration & 146 \\
22 & Dexamethasone implant & 146 \\
23 & Dexamethasone & 135 \\
24 & Risk factor & 125 \\
25 & Photocoagulation & 117 \\
26 & Secondary & 116 \\
27 & Macular edema secondary & 110 \\
28 & Pharmacokinetics & 106 \\
29 & Pars plana vitrectomy & 106 \\
30 & Outcome & 99 \\
& &
\end{tabular}

\subsection{Analysis of Leading Journals and Co-Cited Journals}

In total, 345 academic journals have published papers about steroids in macular edema treatment. Table 2 presented the top 8 journals contributing to this field and Investigative Ophthalmology Visual Science (IOVS) as the leading journal published the most papers (306, 9.407\%), followed by Retina - The Journal of Retinal and Vitreous Diseases (247, 7.593\%), European Journal of Ophthalmology (EJO) (146, 4.488\%), and American Journal of Ophthalmology (AJO) (136, 4.181\%). These are all major ophthalmological journals (Table 2).

The impact factor (IF) represents the importance of journals in particular respective fields, with higher IF indicating publications in that journal with more frequent citations (Mueller et al., 2006). Among these 8 top journals, Ophthalmology has the highest IF (12.079). Co-citation analysis can also measure the degree of relationship between articles. The impact of a journal depends on its co-citation frequency. CiteSpace can show co-citations and annotate cited journals based on citation frequency (Figure 2C). Table 2 presented the top eight journals which were cited over 1,000 times, and consistent with the IF, Ophthalmology has been the most frequently co-cited journal (2,645 times), followed by AJO $(2,327$ times), JAMA Ophthalmology (previously Archives of Ophthalmology) (2,249 times), and Retina - The Journal of Retinal and Vitreous Diseases (2,044 times). According to the journal citation reports (JCR) in 2020 (Clarivate, United Kingdom), seven of the top eight co-cited journals were in the Quartile 1 (Q1), except for Graefes Archive for Clinical and Experimental Ophthalmology (Table 2).

CiteSpace can also show the relationships between citing journals and cited journals in the dual-map overlay of journals (Figure 2D), with dots representing citing journals on the left and cited journals on the right (Chen et al., 2014). The cited relationships are depicted by the colored lines that run from the left to the right side of the dual map. There are five main citation paths, including three pink paths, one orange path, and one green path (Figure 2D). The three pink routes show that Ophthalmology journals mostly cited Molecular or Biology or Genetics, Health or Nursing or Medicine, and Ophthalmology journals. Studies published in Molecular/Biology/ Immunology journals frequently cited articles published in Molecular/Biology/Genetics journals, as indicated by the orange path. The green path indicates that research published in Medicine/Medical/Clinical journals cited papers published in Ophthalmology journals frequently.

\subsection{Analysis of Authors and Co-Cited Authors}

A total of 9,993 authors published papers related to the use of steroids to treat macular edema (Table 3). Bandello F from the Department of Ophthalmology, Vita-Salute San Raffaele University, Italy, had the highest number of published papers (77 publications, 2.367\%), followed by Jonas JB (57, 1.752\%), and Loewenstein A (49, $1.506 \%)$. Table 3 also shows the top 10 most frequently co-cited authors, including Jonas JB (902 times), Haller JA (597 times), and Campochiaro PA (542 times). Jonas JB from the Department of Ophthalmology, Medical Faculty Mannheim of 


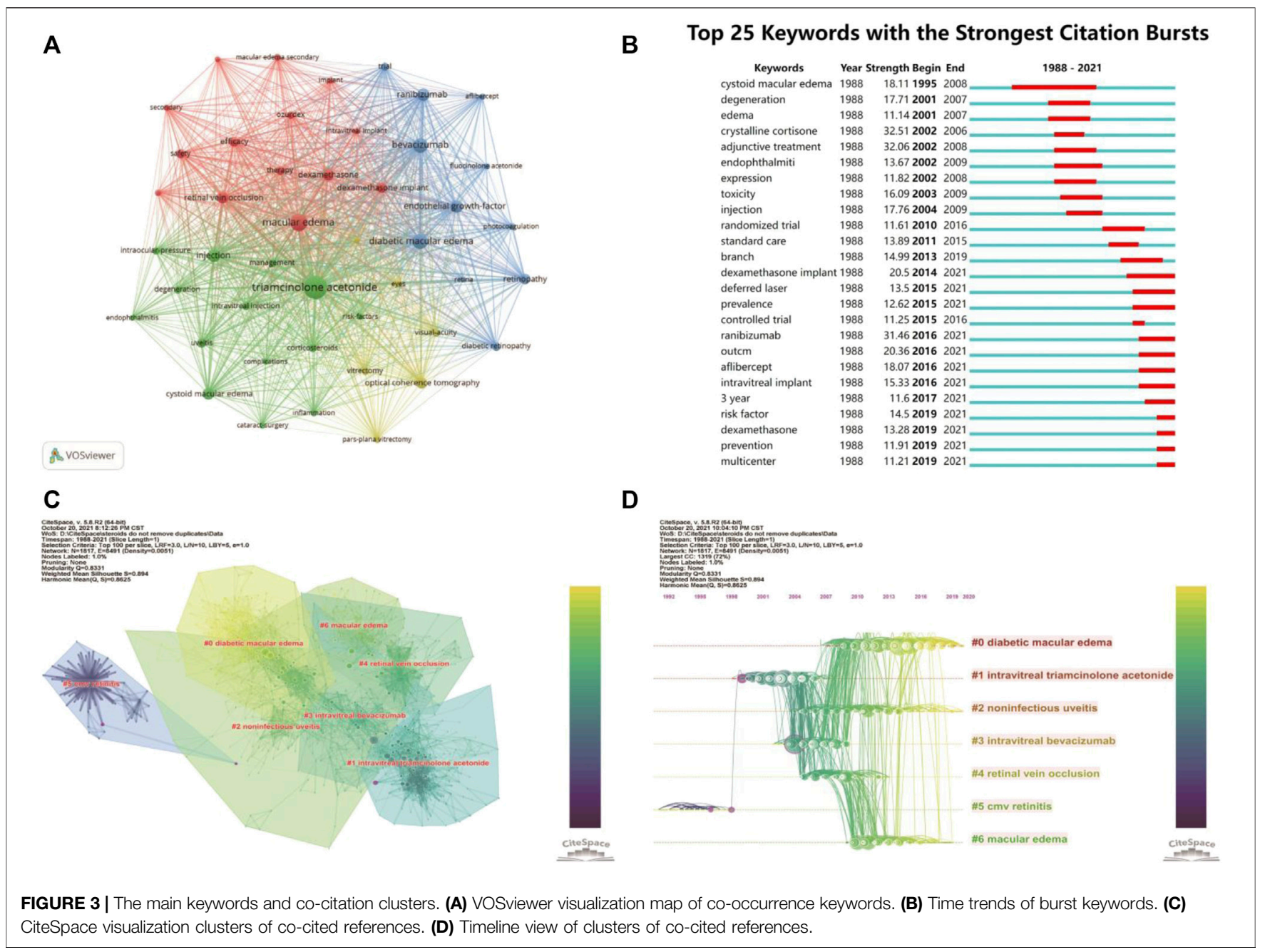

TABLE 5 | Top 12 co-cited references.

\begin{tabular}{|c|c|c|c|c|c|}
\hline No. & $\begin{array}{c}\text { Citation } \\
\text { count }\end{array}$ & Author & Reference title & Journal & Year \\
\hline 1 & 272 & Boyer DS & $\begin{array}{l}\text { Three-year, randomized, sham-controlled trial of dexamethasone intravitreal implant in patients } \\
\text { with diabetic macular edema. }\end{array}$ & Ophthalmology & 2014 \\
\hline 3 & 177 & Jonas JB & Intravitreal injection of triamcinolone for diffuse diabetic macular edema. & $\begin{array}{l}\text { Arch Ophthalmol- } \\
\text { Chic }\end{array}$ & 2003 \\
\hline 4 & 153 & Haller JA & $\begin{array}{l}\text { Randomized, sham-controlled trial of dexamethasone intravitreal implant in patients with macular } \\
\text { edema due to retinal vein occlusion. }\end{array}$ & Ophthalmology & 2010 \\
\hline 6 & 141 & Massin $\mathrm{P}$ & $\begin{array}{l}\text { Intravitreal triamcinolone acetonide for diabetic diffuse macular edema - Preliminary results of a } \\
\text { prospective controlled trial. }\end{array}$ & Ophthalmology & 2004 \\
\hline 7 & 132 & Wells JA & Aflibercept, bevacizumab, or ranibizumab for diabetic macular edema. & New Engl J Med & 2015 \\
\hline 8 & 119 & Greenberg PB & Intravitreal triamcinolone acetonide for macular oedema due to central retinal vein occlusion. & Brit J Ophthalmol & 2002 \\
\hline 9 & 115 & Antcliff RJ & $\begin{array}{l}\text { Intravitreal triamcinolone for uveitic cystoid macular edema: An optical coherence tomography } \\
\text { study. }\end{array}$ & Ophthalmology & 2001 \\
\hline 12 & 102 & $\begin{array}{l}\text { Campochiaro } \\
\text { PA }\end{array}$ & $\begin{array}{l}\text { Sustained delivery fluocinolone acetonide vitreous inserts provide benefit for at least } 3 \text { years in } \\
\text { patients with diabetic macular edema. }\end{array}$ & Ophthalmology & 2012 \\
\hline
\end{tabular}


TABLE 6 | Cited papers with the highest "betweenness centrality" among the top 7 clusters.

\begin{tabular}{lc}
\hline Rank & Centrality \\
\hline 1 & 0.41 \\
2 & 0.41 \\
3 & 0.39 \\
4 & 0.16 \\
5 & 0.1
\end{tabular}

Cluster \#

Wingate and Beaumont. (1999): Intravitreal triamcinolone and elevated intraocular pressure.

Rothova. (1996): Causes and frequency of blindness in patients with intraocular inflammatory disease.

Challa et al. (1998): Exudative macular degeneration and intravitreal triamcinolone: 18 months follow up.

Jonas et al. (2003b): Intraocular pressure after intravitreal injection of triamcinolone acetonide.

Massin. (2004): Intravitreal triamcinolone acetonide for diabetic diffuse macular edema: preliminary results of a prospective controlled trial.

the Ruprecht-Karls-University, Heidelberg, Germany, was ranked the second most productive author and the first on the most co-cited list, placing him among the top ten in both lists. Another author ranked highly on both lists was Gillies MC (Sydney Eye Hospital, Sydney, Australia).

\subsection{Analysis of Co-Occurring Keywords and Burst Term}

Keywords analysis can reveal hotspots in a topic of study. We merged some different versions of the same terms when we analyzed the keywords, including synonyms (e.g., "triamcinolone acetonide" and "triamcinolone"), different spelling versions (e.g., "triamcinolone acetonide" and "triamcinoloneacetonide"), and abbreviated terms (e.g., "DME" and "diabetic macular edema"). Table 4 shows the top 30 keywords, with most of them falling into two categories. Macular edema and disorders associated with macular edema, such as diabetic macular edema (DME), cystoid macular edema (CME), and $\mathrm{RVO}$, are covered in the disease category. The other group is macular edema therapy, including keywords like TA, injections, and bevacizumab. The rest of the top 30 keywords are related to the efficacy and safety of these treatments. Interestingly, half of the top 6 keywords are VEGF-related terms (Bevacizumab, Endothelial growth factor, and Ranibizumab) (Table 4), suggesting anti-VEGF therapy and steroids therapy in macular edema were often connected. In Figure 3A, we used VOSviewer software to show the primary keywords more compact and aesthetically pleasing.

We also used CiteSpace's burst detection function to discover the top 25 terms with the most citation bursts (Figure 3B). A blue line displays the time interval, whereas a red line segment depicts the burst period time of keywords. Similarly, most of the top 25 burst keywords may be classified as disorders connected to macular edema and its treatment. Keywords associated with macular edema, such as cystoid macular edema, degeneration, and edema, began to burst during the early stages. Following that, keywords like crystalline cortisone and adjunctive treatment began to explode, showing that the study focus had shifted to finding solutions to these perplexing issues. Also worth noting, intravitreal implant and VEGF-related terms only had bursts recently (Figure 3B).

\subsection{Co-cited References and Burst References}

\subsubsection{Top-Cited References}

The most distinctive feature of CiteSpace is co-cited references analysis, resulting in a broad perspective of a scientific subject by selecting the top 100 most cited publications published over 1 year. We compiled a list of the top 12 co-cited references from 1988 to 2021 (Table 5). These references were cited more than 100 times, with the top two receiving more than 200 citations each. The most frequently cited reference was a report on clinical trials (registered with the identifiers NCT00168337 and NCT00168389 at ClinicalTrials.gov), reporting the safety and efficacy of dexamethasone intravitreal implant (Ozurdex, DEX implant) 0.7 and $0.35 \mathrm{mg}$ in the treatment of DME (Boyer et al., 2014). The second most cited paper also reported the results of the intravitreal triamcinolone acetonide (IVTA) clinical trial for treating refractory DME that did not respond well to photocoagulation (Martidis et al., 2002).

\subsubsection{Seven Clusters of Co-citation Network}

CiteSpace could potentially partition the co-citation network into clusters, displaying firmly related references in one cluster and loosely connected references in another. Words from the titles of the citing articles inside the cluster were used to designate each cluster. The top seven clusters were shown in Figure 3C, including \#0 diabetic macular edema, \#1 intravitreal triamcinolone acetonide, \#2 noninfectious uveitis, \#3 intravitreal bevacizumab, \#4 retinal vein occlusion, \#5 cmv retinitis, and \#6 macular edema. These included four clusters about the macular edema-related diseases (clusters \#0,2, 4, and 6 ), one cluster about IVTA, one about anti-VEGF, and one about complications related to steroids treatment (\#5 CMV retinitis).

\subsubsection{Timeline Cluster Map}

The cluster map could be converted into a timeline format, using the cluster number as the $y$-axis (Figure 3D). The timeline diagram depicted the progression of research in the general field and its seven sub-fields over time. Notably, cluster \#5 CMV retinitis was mainly in the early time, and never overlapped with other clusters (Figure 3D); suggesting CMV retinitis is not a major complication of steroids in macular edema treatment. Cluster \#0 (DME), \#2 (noninfectious uveitis), and \#6 (ME, actually mainly about RVO) persisted to recent time, indicating these three ocular diseases are primary indications for steroids therapy of macular edema now (Figure 3D)

\subsubsection{High Betweenness Centrality Papers}

Some nodes in the timeline-cluster map had purple rings around them, indicating that they had high "betweenness centrality" ratings, which is defined as the number of times a node lies on the shortest path between all pairs of nodes (Abbasi et al., 
TABLE 7 | Cited references and citing articles of Cluster \#1 intravitreal triamcinolone acetonide.

Cluster \#1 intravitreal triamcinolone acetonide

\begin{tabular}{|c|c|c|c|}
\hline \multicolumn{2}{|r|}{ Cited references } & \multicolumn{2}{|r|}{ Citing articles } \\
\hline \multirow{2}{*}{$\begin{array}{l}\text { Citation } \\
\text { count }\end{array}$} & Author (Year) Journal & Coverage & \multirow[t]{2}{*}{ Author (Year) title } \\
\hline & Volume, Page & Count & \\
\hline 200 & $\begin{array}{l}\text { Martidis et al. (2002) Ophthalmology, } \\
109,920\end{array}$ & 108 & Jonas. (2006) Intravitreal triamcinolone acetonide: a change in a paradigm. \\
\hline 177 & $\begin{array}{l}\text { Jonas et al., 2003a Arch Ophthalmol-Chic, } \\
\text { 121, } 57\end{array}$ & 91 & $\begin{array}{l}\text { Jonas. (2005) Intravitreal triamcinolone acetonide for treatment of intraocular oedematous and } \\
\text { neovascular diseases. }\end{array}$ \\
\hline 119 & $\begin{array}{l}\text { Greenberg et al. (2002) Brit J Ophthalmol, } \\
86,247\end{array}$ & 88 & $\begin{array}{l}\text { Jonas. (2005) Intravitreal triamcinolone acetonide for treatment of intraocular proliferative, } \\
\text { exudative, and neovascular diseases. }\end{array}$ \\
\hline 115 & Antcliff. (2001) Ophthalmology, 108, 765 & 60 & $\begin{array}{l}\text { Jonas et al. (2004) Intravitreal triamcinolone acetonide for the treatment of intraocular } \\
\text { edematous and neovascular diseases. }\end{array}$ \\
\hline 111 & Jonas et al. (2003b) Brit J Ophthalmol, 87, 24 & 45 & $\begin{array}{l}\text { Jonas et al., 2003c Treatment of oedematous, proliferative and neovascular diseases by } \\
\text { intravitreal triamcinolone acetonide. }\end{array}$ \\
\hline 97 & $\begin{array}{l}\text { Jonas and Söfker. (2001) Am J Ophthalmol, } \\
\text { 132, } 425\end{array}$ & 45 & $\begin{array}{l}\text { Thompson, (2006) Cataract formation and other complications of intravitreal triamcinolone for } \\
\text { macular edema. }\end{array}$ \\
\hline
\end{tabular}

TABLE 8 | Cited references and citing articles of Cluster \#0 diabetic macular edema.

Cluster \#0 diabetic macular edema

\begin{tabular}{|c|c|c|c|}
\hline \multicolumn{2}{|r|}{ Cited references } & \multicolumn{2}{|r|}{ Citing articles } \\
\hline \multirow{2}{*}{$\begin{array}{l}\text { Citation } \\
\text { count }\end{array}$} & Author (Year) Journal & Coverage & \multirow[t]{2}{*}{ Author (Year) title } \\
\hline & Volume, Page & Count & \\
\hline 272 & Boyer. (2014) Ophthalmology, 121,1904 & 40 & Cicinelli, Maria Vittoria (2020) The current role of steroids in diabetic macular edema. \\
\hline 132 & $\begin{array}{l}\text { Wells et al. (2015) New Engl J Med, 372, } \\
1193\end{array}$ & 36 & Bandello, Francesco (2013) Pathophysiology and treatment of diabetic retinopathy. \\
\hline 102 & $\begin{array}{l}\text { Campochiaro et al. (2012) Ophthalmology, } \\
119,2125\end{array}$ & 31 & Bandello et al. (2014) Pharmacological approach to diabetic macular edema. \\
\hline 98 & $\begin{array}{l}\text { Nguyen et al. (2012) Ophthalmology, } \\
119,789\end{array}$ & 31 & $\begin{array}{l}\text { Cebeci, Zafer (2015) Role of implants in the treatment of diabetic macular edema: focus on the } \\
\text { dexamethasone intravitreal implant. }\end{array}$ \\
\hline 92 & $\begin{array}{l}\text { Chang-Lin et al. (2011) Invest Ophth Vis Sci, } \\
52,80\end{array}$ & 29 & $\begin{array}{l}\text { Urbancic, Mojca (2019) Dexamethasone implant in the management of diabetic macular } \\
\text { edema from clinician's perspective. }\end{array}$ \\
\hline 91 & $\begin{array}{l}\text { Boyer et al. (2011) Retina-J Ret Vit Dis, } \\
31,915\end{array}$ & 29 & Lambiase et al. (2014) An update on intravitreal implants in use for eye disorders. \\
\hline
\end{tabular}

TABLE 9 | Cited references and citing articles of Cluster \#2 noninfectious uveitis.

Cluster \#2 noninfectious uveitis

\begin{tabular}{|c|c|c|c|}
\hline \multicolumn{2}{|r|}{ Cited references } & \multicolumn{2}{|r|}{ Citing articles } \\
\hline \multirow{2}{*}{$\begin{array}{l}\text { Citation } \\
\text { count }\end{array}$} & Author (Year) Journal & Coverage & \multirow[t]{2}{*}{ Author (Year) title } \\
\hline & Volume, Page & Count & \\
\hline 107 & $\begin{array}{l}\text { Lowder et al. (2011) Arch Ophthalmol-Chic, } \\
\text { 129, } 545\end{array}$ & 24 & $\begin{array}{l}\text { Heiligenhaus et al. (2014) Statement of the german ophthalmological society, of the } \\
\text { retinological society and the professional association of german oculist for intravitreal } \\
\text { therapy for makulaodems in uveitis. }\end{array}$ \\
\hline 58 & $\begin{array}{l}\text { Kuppermann et al. (2007) Arch Ophthalmol- } \\
\text { Chic, 125, } 309\end{array}$ & 24 & $\begin{array}{l}\text { Heiligenhaus et al. (2014) Statement of the german ophthalmological society, the retina } \\
\text { society and the professional association of eye doctors in germany for intravitreal treatment } \\
\text { of macular edema in uveitis. }\end{array}$ \\
\hline 50 & Kiddee et al. (2013) Surv Ophthalmol, 58, 291 & 19 & Lambiase et al. (2014) An update on intravitreal implants in use for eye disorders. \\
\hline 40 & $\begin{array}{l}\text { Tomkins-Netzer et al. (2014) Ophthalmology, } \\
121,1649\end{array}$ & 19 & $\begin{array}{l}\text { Ossewaarde-van Norel, Annette (2011) Clinical review: update on treatment of inflammatory } \\
\text { macular edema. }\end{array}$ \\
\hline 36 & Khurana et al. (2014) Ophthalmology, 121, 67 & 18 & $\begin{array}{l}\text { Robinson, Michael R (2012) Pharmacologic and clinical profile of dexamethasone intravitreal } \\
\text { implant. }\end{array}$ \\
\hline
\end{tabular}


TABLE 10 | Cited references and citing articles of Cluster \#4 retinal vein occlusion.

Cluster \#4 retinal vein occlusion

\begin{tabular}{|c|c|c|c|}
\hline \multicolumn{2}{|r|}{ Cited references } & \multicolumn{2}{|r|}{ Citing articles } \\
\hline \multirow{2}{*}{$\begin{array}{l}\text { Citation } \\
\text { count }\end{array}$} & Author (Year) Journal & Coverage & \multirow[t]{2}{*}{ Author (Year) title } \\
\hline & Volume, Page & Count & \\
\hline 92 & $\begin{array}{l}\text { Ip et al. (2009) Arch Ophthalmol-Chic, 127, } \\
1101\end{array}$ & 41 & $\begin{array}{l}\text { Feltgen et al. (2010) Intravitreal drug therapy for retinal vein occlusion - pathophysiological } \\
\text { mechanisms and routinely used drugs. }\end{array}$ \\
\hline 88 & $\begin{array}{l}\text { Scott et al. (2009) Arch Ophthalmol-Chic, } \\
127,1115\end{array}$ & 33 & Macdonald, Derek (2014) The abcs of rvo: a review of retinal venous occlusion. \\
\hline 57 & $\begin{array}{l}\text { Iturralde et al. (2006) Retina-J Ret Vit Dis, } \\
26,279\end{array}$ & 33 & $\begin{array}{l}\text { Chatziralli, Irini P (2014) Branch retinal vein occlusion: treatment modalities: an update of the } \\
\text { literature. }\end{array}$ \\
\hline 43 & Jonas. (2005) Eye, 19, 65 & 26 & $\begin{array}{l}\text { Siegel, Ruth Axer (2012) Intravitreal bevacizumab treatment for macular edema due to branch } \\
\text { retinal vein occlusion in a clinical setting. }\end{array}$ \\
\hline 34 & $\begin{array}{l}\text { Rosenfeld et al. (2005) Ophthal Surg Las Im, } \\
\text { 36, } 336\end{array}$ & 21 & Sarao et al. (2014) Pharmacotherapy for treatment of retinal vein occlusion. \\
\hline 33 & $\begin{array}{l}\text { Rabena et al. (2007) Retina-J Ret Vit Dis, } \\
27,419\end{array}$ & 21 & $\begin{array}{l}\text { Braithwaite, T (2010) Anti-vascular endothelial growth factor for macular edema secondary to } \\
\text { central retinal vein occlusion. }\end{array}$ \\
\hline 29 & $\begin{array}{l}\text { Prager et al. (2009) Brit J Ophthalmol, } \\
93,452\end{array}$ & 21 & $\begin{array}{l}\text { Shahsuvaryan, Marianne L (2012) Therapeutic potential of intravitreal pharmacotherapy in retinal } \\
\text { vein occlusion. }\end{array}$ \\
\hline
\end{tabular}

TABLE 11 | Cited references and citing articles of Cluster \#6 macular edema.

Cluster \#6 macular edema

\begin{tabular}{|c|c|c|c|}
\hline \multicolumn{2}{|r|}{ Cited references } & \multicolumn{2}{|r|}{ Citing articles } \\
\hline \multirow{2}{*}{$\begin{array}{l}\text { Citation } \\
\text { count }\end{array}$} & Author (Year) Journal & Coverage & \multirow[t]{2}{*}{ Author (Year) title } \\
\hline & Volume, Page & Count & \\
\hline 153 & $\begin{array}{l}\text { Haller et al. (2010) Ophthalmology, 117, } \\
1134\end{array}$ & 27 & Macdonald, Derek (2014) The abcs of rvo: a review of retinal venous occlusion. \\
\hline 149 & $\begin{array}{l}\text { Haller et al. (2011) Ophthalmology, 118, } \\
2453\end{array}$ & 20 & $\begin{array}{l}\text { Wang, Jia-Kang (2016) A review of randomized trials of approved pharmaceutical agents for } \\
\text { macular edema secondary to retinal vein occlusion. }\end{array}$ \\
\hline 70 & $\begin{array}{l}\text { Brown et al. (2011) Ophthalmology, 117, } \\
1124^{\mathrm{a}}\end{array}$ & 17 & $\begin{array}{l}\text { Garweg, Justus G (2016) Retinal vein occlusion and the use of a dexamethasone intravitreal } \\
\text { implant (ozurdexa (r)) in its treatment. }\end{array}$ \\
\hline 65 & $\begin{array}{l}\text { Campochiaro et al. (2010) Ophthalmology, } \\
117,1102\end{array}$ & 17 & $\begin{array}{l}\text { Ramezani, Alireza (2014) Three intravitreal bevacizumab versus two intravitreal triamcinolone } \\
\text { injections in recent onset central retinal vein occlusion. }\end{array}$ \\
\hline 49 & $\begin{array}{l}\text { Campochiaro et al. (2011) Ophthalmology, } \\
118,2041\end{array}$ & 17 & Sarao et al. (2014) Pharmacotherapy for treatment of retinal vein occlusion. \\
\hline 48 & $\begin{array}{l}\text { Capone et al. (2014) Retina-J Ret Vit Dis, } \\
34,342\end{array}$ & 17 & $\begin{array}{l}\text { Coscas, Gabriel (2014) Retreatment with ozurdex for macular edema secondary to retinal vein } \\
\text { occlusion. }\end{array}$ \\
\hline 47 & $\begin{array}{l}\text { Brown et al. (2011) Ophthalmology, 118, } \\
1594\end{array}$ & 17 & $\begin{array}{l}\text { Maggioa, Emilia (2014) Intravitreal dexamethasone implant for macular edema secondary to } \\
\text { retinal vein occlusion: 12-month follow-up and prognostic factors. }\end{array}$ \\
\hline
\end{tabular}

${ }^{a}$ Here, we need to mention that CiteSpace could only analyze the publications in the WOS core collection database, so we only downloaded these publications. However, the references cited by these articles may not be collected in this database, so information on such references would have some discrepancies. In this cluster, the third cited reference was not the one listed in the results of CiteSpace, and it was only collected by the Medline database rather than the WOS Core Collection database. Actually, the primary one given by CiteSpace was a letter by the same author team to reply to some questions about the treatment of age-related macular degeneration by using ranibizumab, which was obviously irrelative with our research topic. Additionally, CiteSpace also gave a DOI number that did not match this article, but the number helped us to find out the matched and right article shown in Table $\mathbf{9}$ with an asterisk. Because this article was published by the same team as the fourth, fitth, and seventh articles in Table 9, and they were all reports of the efficacy and safety results of the clinical trials about the treatment of RVO-induced macular edema by using ranibizumab, so we used this article to replace the former one instead of straight deleting it in Table $\mathbf{9}$.

2011). The top five papers with higher "betweenness centrality" are shown in Table 6. These papers may suggest some emerging trends in this field. Interestingly, two of them published 20 years ago belong to cluster \#5 (CMV retinitis). The other three papers are all about IVTA or its complication (glaucoma), suggesting prevention of ocular complications of steroids is still essential now.

\subsubsection{Details of Cluster \#1 (IVTA)}

In cluster \#1 (IVTA), Jonas JB was the author of half of the top six co-cited references (Table 7), including a case report and two clinical trial articles (Jonas et al., 2003a; Jonas et al., 2003b; Jonas and Söfker, 2001). He was also the author of the top five citing articles, citing most publications in this field (coverage count) (Table 7). All these five citing papers were reviews, and two were in German (Jonas et al., 2003c; Jonas et al., 2004; Jonas et al., 2005a; Jonas, 2005; Jonas, 2006). As previously stated, Jonas JB ranked first among the most cited authors, and we now know that he made a significant contribution to the treatment of DME using IVTA. The clinical article by Martidis et al. published in 2002 was the most prominent in cluster \#1 (IVTA). Unlike Jonas JB's 
clinical trial papers, all of the patients involved in this investigation had received at least two prior sessions of laser photocoagulation yet still showed residual macular edema (Martidis et al., 2002).

\subsubsection{Details of Cluster \#0 (DME), Cluster \#2 (Noninfectious Uveitis), Cluster \#4 (RVO) and Cluster \#6 (Macular Edema)}

Macular edema can be caused by a variety of ocular diseases, including DME, uveitis, and RVO (Cunningham et al., 2008). In cluster \#0 (DME) (Table 8), the paper about dexamethasone intravitreal implant (Boyer et al., 2014) was the top-cited reference, and it was also the top co-cited reference among all clusters (Table 5). In cluster \#2 (noninfectious uveitis), the paper about dexamethasone intravitreal implant for uveitis was the most cited reference (Lowder et al., 2011), which indicated that DEX implant was safe and effective for the treatment of intermediate and posterior uveitis (Table 9). By employing the DEX implant, they were able to make a significant contribution to the treatment of uveitic macular edema. Regardless of the citing articles or references, all of the publications in cluster \#4 (RVO) and cluster \#6 (macular edema) were about the treatment of macular edema caused by RVO (Table 10 and Table 11). These two clusters of co-cited references were all clinical trials or case reports examining the efficacy and safety of medications to treat RVO-induced macular edema. Apart from IVTA, two other therapies were used: DEX implant and ranibizumab. DEX implant is a slow-releasing biodegradable implant indicated for injection every 6 months and is a combination of medication and drug delivery mechanisms (Gaballa et al., 2021). Ranibizumab is a recombinant monoclonal antibody that can block VEGF-A (Rosenfeld et al., 2006).

\section{DISCUSSION}

The first article on this research topic was published in 1988, which described the successful use of steroids drops and subTenon injection to treat cystoid macular edema (CME) following cataract extraction (Suckling and Maslin, 1988), suggesting that local steroids are effective in the treatment of pseudophakic CME. However, only a few studies were published over the next decade, mainly about systemic steroids on uveitis-related macular edema (Nussenblatt et al., 1991), steroid-induced ocular complications in the treatment of aphakic or pseudophakic CME (Melberg and Olk, 1993), and steroids sub-Tenon injections in uveitis patients with cystoid macular edema (Yoshikawa et al., 1995). CME was the top keyword during that time (Figure 3B). Steroid research in macular edema was still in its infancy at that time.

The first research wave lasting for one decade began from 2003 (Figure 2A), shortly after the first reports of human intravitreal injections of crystalline cortisone in the treatment of DME (Jonas and Söfker, 2001), IVTA for uveitic cystoid macular edema (Antcliff et al., 2001), IVTA for macular edema due to CRVO (Greenberg et al., 2002) and refractory DME (Martidis et al., 2002). These four papers are pioneering works, coming from Europe (Jonas and Söfker, 2001; Antcliff et al., 2001) and the
United States (Martidis et al., 2002; Greenberg et al., 2002), and are all top-cited in this field (Table 5). At this time, the average publication per year on this topic was more than 110 papers. The second research wave lasting almost another decade began from 2013 to 2014 (Figure 2A), the average publication per year on this topic was more than 220 papers. This wave of research may be prompted by good results of the MEAD study demonstrating the efficacy of dexamethasone implant in the treatment of DME (Boyer et al., 2014), and the FDA-approved use of sustainedrelease biodegradable dexamethasone (Ozurdex) for the treatment of DME in 2014. The paper of the MEAD trial is the top-cited reference among all publications in this field (Boyer et al., 2014).

From the perspective of countries and authors, the United States was the leading contributor in this field with 913 publications, followed by Germany and Italy (Table 1). The top three countries were all developed countries in Europe and America. The research output from these countries may be associated with major pioneer researchers in this field and substantial financial support. Indeed, most of the top authors and co-cited authors were from Europe and America (Table 3). Europe and American researchers initiated both waves of research in this field. Among the top 10 countries, there are four countries from Asia (Japan, South Korea, India, and China), likely due to the vast number of patients in Asia. Sakamoto T was the only top-productive author from these countries; however, no top-cited authors came from these countries (Table 3).

Bandello $F$ published the most papers. His significant contribution to this field is three clinical trials regarding the use of DEX intravitreal implant in macular edema caused by RVO (Haller et al., 2010; Haller et al., 2011) and DME (Boyer et al., 2014). Following Bandello F, Jonas JB, Loewenstein A, Scott IU, Whitcup $\mathrm{SM}$ and Gillies MC were the top six most productive authors with cooperative relationships. Jonas JB and Gillies MC were also topcited authors (Table 3). Jonas JB is a comprehensive ophthalmologist and Chairman of the Department of Ophthalmology of the Medical Faculty Mannheim of Heidelberg University. His major contribution to this field is the first report on intravitreal injections of crystalline cortisone in the treatment of DME patients (Jonas and Söfker, 2001), IVTA for DME (Jonas et al., 2003a; Jonas et al., 2006), and IVTA-induced intraocular pressure (Jonas et al., 2003b; Jonas et al., 2005b). Gillies MC is a Professor at Save Sight Institute, University of Sydney. His major contribution to this field is similar to Bandello F, including the use of DEX intravitreal implant in macular edema caused by RVO (Haller et al., 2010; Haller et al., 2011) and DME (Sutter et al., 2004; Gillies et al., 2006). These researchers are considered world leaders in this critical research field and their studies will continue to influence the future development of steroids in the treatment of macular edema.

From the perspective of journals and co-cited journals, IOVS published the most papers, followed by Retina, EJO, and AJO. The average number of citations for each document is up to 20 times, which fully indicates that researchers obtained international recognition in this field. Co-citation analysis revealed that Ophthalmology had been the most co-cited journal (Table 2), with the highest impact factor. Indeed, more than half of the 12 top-cited 
references in this field were published in Ophthalmology (Table 5), all about clinical trials regarding DEX implants (Haller et al., 2010; Haller et al., 2011; Boyer et al., 2014), IVTA (Antcliff et al., 2001; Martidis et al., 2002; Massin et al., 2004), and FA inserts (Campochiaro et al., 2012). These studies significantly promote the safety and efficacy of steroids use in treating of macular edema.

Keywords can provide immediate information about hotspots in the field. Word analysis can show how the research concepts evolve during a period. In our study, keywords analysis showed that the high-frequency keywords belong to the disease category (including DME, RVO) and therapy category (including TA, DEX implant, and VEGF-related terms). Interestingly, intravitreal implant and VEGFrelated terms were among these top keywords and had bursts recently (Figure 3B). These keywords captured this field's current and future direction (Sacconi et al., 2019). Anti-VEGF agents, including bevacizumab, ranibizumab, and aflibercept, are the first-line treatment for DME (Brown et al., 2013; Wells et al., 2015) and macular edema secondary to RVO (Boyer et al., 2012; Holz et al., 2013; Schmidt-Erfurth et al., 2019). While they are more effective and have fewer side effects than steroids (Gao et al., 2019), a significant proportion of patients do not respond well and repeated intravitreal injections are required to maintain the visual benefits (Engman et al., 2011). Steroids generally only have short-term effects, but new DEX and FA sustained-release devices have been developed, such as Ozurdex (DEX implant), Iluvien (FA implant), and YUTIQ (FA implant) (Testi and Pavesio, 2019; McGregor et al., 2021), which offer a longer duration of action and can reduce the number of intravitreal injections required (DEX for 4-6 months; FA for 3 years) (Bandello et al., 2014). These steroids implants or inserts are commonly used as a second-line treatment for DME patients without significant response to anti-VEGF therapies (Tan et al., 2017; He et al., 2018; Fallico et al., 2021), but are also considered as valid therapeutic options in the treatment of RVO-induced macular edema because of their anti-inflammatory, anti-angiogenic, and antiedema properties (Haller et al., 2010; Haller et al., 2011; CastroNavarro et al., 2021). Although some patients require repeated steroid injections, the long duration between treatments is still a considerable advantage of these drugs (Scaramuzzi et al., 2015).

Betweenness centrality results from cluster analysis of co-citation network identified important papers about complications of ocular steroids treatment (Table 6). Although CMV retinitis was mainly reported almost 20 years ago based on the timeline-cluster map (Figure 3D), it was frequently reported recently in patients receiving intravitreal injection of steroids (such as IVTA) or steroids implants (Jaissle et al., 2004; Saidel et al., 2005; Ufret-Vincenty et al., 2007; Witmer and Connolly, 2021). Increased intraocular pressure (IOP) and cataract formation are common side effects of various types of steroids (Jonas et al., 2005b; Yang et al., 2015). According to a Cochrane systematic review, cataracts progressed in 5 or 6 out of 10 patients treated with steroids, and IOP increased in roughly 3 out of 10 patients, which is significantly greater than the control group (Rittiphairoj et al., 2020). These possible side effects must be carefully monitored when using steroids to treat macular edema.

By systematically combining the publications during the past three decades, we show the dynamic development process, hotspots, research trends, and structural relationship of different aspects of steroids treatment of macular edema. There are some limits to this study. First, the analysis of this study is only based on publications in the WOS core collection database. Although this collection includes most of the research publications in this field, other databases may provide broader coverage, such as PubMed and Scopus. Second, the research results of this paper are completed based on CiteSpace and VOSviewer, and the machine algorithm may not be perfect and can induce some bias. For instance, IVTA is a major cluster in the keyword and cluster analysis (Figures 3C,D), DEX and FA, on the other hand, are only found on the periphery of the term visualization map and do not even make the top ten in cluster analysis. However, the number of IVTA publications has decreased dramatically, while DEX and FA implants have received increasing attention in recent clinical trials (Castro-Navarro et al., 2021; Fallico et al., 2021). This trend has not been captured in our study.

Combined therapy with anti-VEGF and suprachoroidal corticosteroids may overcome the limits of both agents and increase the therapeutic efficacy (Sacconi et al., 2019). Our study also misses this trend, as many new clinical trials on these strategies are currently being conducted, and results are not published yet. More outcomes from these trials will help us build a better approach for treating macular edema in the future after balancing the benefits and limits of various therapeutic strategies and the patient's medical needs.

\section{CONCLUSION}

We are at the second research wave of using steroids to treat macular edema with more than 200 publications every year. The United States and Europe led in this field by contributing the most important papers. Papers published in a specialty journal such as Ophthalmology will attract more attention than papers published in comprehensive journals. While anti-VEGF therapy is the first-line treatment for DME and RVO-induced macular edema, steroids implant is a valid option for these DME patients not responding to anti-VEGF therapy and non-DME patients with macular edema. Combined therapy with anti-VEGF and steroids agents is essential for future research.

\section{DATA AVAILABILITY STATEMENT}

The raw data supporting the conclusions of this article will be made available by the authors, without undue reservation.

\section{AUTHOR CONTRIBUTIONS}

YL and DC designed the study. All authors conducted the literature search and analyzed the data. YL, XR, and DC wrote and revised the manuscript. All authors contributed to the article and approved the submitted version.

\section{FUNDING}

This work was supported by grants to DC from the National Natural Science Foundation of China (81870665, 82171063). 


\section{REFERENCES}

Abbasi, A., Altmann, J., and Hossain, L. (2011). Identifying the Effects of Coauthorship Networks on the Performance of Scholars: A Correlation and Regression Analysis of Performance Measures and Social Network Analysis Measures. J. Informetrics 5, 594-607. doi:10.1016/j.joi.2011.05.007

Aksu-Ceylan, N., Cebeci, Z., Altinkurt, E., Kir, N., Oray, M., and Tugal-Tutkun, I. (2021). Interferon Alpha-2a for the Treatment of Cystoid Macular Edema Secondary to Acute Retinal Necrosis. Ocul. Immunol. Inflamm., 1-10. [online ahead of print]. doi:10.1080/09273948.2021.1957121

Antcliff, R. J., Spalton, D. J., Stanford, M. R., Graham, E. M., ffytche, T. J., and Marshall, J. (2001). Intravitreal Triamcinolone for Uveitic Cystoid Macular Edema: an Optical Coherence Tomography Study. Ophthalmology 108 (4), 765-772. doi:10.1016/s0161-6420(00)00658-8

Aref, A. A., Scott, I. U., VanVeldhuisen, P. C., King, J., Ip, M. S., Blodi, B. A., et al. (2021). Intraocular Pressure-Related Events after Anti-vascular Endothelial Growth Factor Therapy for Macular Edema Due to Central Retinal Vein Occlusion or Hemiretinal Vein Occlusion: SCORE2 Report 16 on a Secondary Analysis of a Randomized Clinical Trial. JAMA Ophthalmol. 139, 1285-1291. doi:10.1001/jamaophthalmol.2021.4395

Bandello, F., Preziosa, C., Querques, G., and Lattanzio, R. (2014). Update of Intravitreal Steroids for the Treatment of Diabetic Macular Edema. Ophthalmic Res. 52 (2), 89-96. doi:10.1159/000362764

Boyer, D., Heier, J., Brown, D. M., Clark, W. L., Vitti, R., Berliner, A. J., et al. (2012). Vascular Endothelial Growth Factor Trap-Eye for Macular Edema Secondary to central Retinal Vein Occlusion: Six-Month Results of the Phase 3 COPERNICUS Study. Ophthalmology 119 (5), 1024-1032. doi:10.1016/j. ophtha.2012.01.042

Boyer, D. S., Faber, D., Gupta, S., Patel, S. S., Tabandeh, H., Li, X. Y., et al. (2011). Dexamethasone Intravitreal Implant for Treatment of Diabetic Macular Edema in Vitrectomized Patients. Retina 31 (5), 915-923. doi:10.1097/IAE. 0b013e318206d18c

Boyer, D. S., Yoon, Y. H., Belfort, R., Bandello, F., Maturi, R. K., Augustin, A. J., et al. (2014). Three-year, Randomized, Sham-Controlled Trial of Dexamethasone Intravitreal Implant in Patients with Diabetic Macular Edema. Ophthalmology 121 (10), 1904-1914. doi:10.1016/j.ophtha.2014.04.024

Brown, D. M., Campochiaro, P. A., Bhisitkul, R. B., Ho, A. C., Gray, S., Saroj, N., et al. (2011). Sustained Benefits From Ranibizumab for Macular Edema Following Branch Retinal Vein Occlusion: 12-Month Outcomes of a Phase III Study. Ophthalmology 118 (8), 1594-1602. doi:10.1016/j.ophtha.2011.02.022

Brown, D. M., Campochiaro, P. A., Singh, R. P., Li, Z., Gray, S., Saroj, N., et al. (2010). Ranibizumab for Macular Edema Following Central Retinal Vein Occlusion: Six-Month Primary End Point Results of a Phase III Study. Ophthalmology 117 (6), 1124-1133.e1. doi:10.1016/j.ophtha.2010.02.022

Brown, D. M., Nguyen, Q. D., Marcus, D. M., Boyer, D. S., Patel, S., Feiner, L., et al. (2013). Long-term Outcomes of Ranibizumab Therapy for Diabetic Macular Edema: the 36-month Results from Two Phase III Trials: RISE and RIDE. Ophthalmology 120 (10), 2013-2022. doi:10.1016/j.ophtha.2013.02.034

Bucolo, C., Gozzo, L., Longo, L., Mansueto, S., Vitale, D. C., and Drago, F. (2018). Long-term Efficacy and Safety Profile of Multiple Injections of Intravitreal Dexamethasone Implant to Manage Diabetic Macular Edema: A Systematic Review of Real-World Studies. J. Pharmacol. Sci. 138 (4), 219-232. doi:10.1016/ j.jphs.2018.11.001

Campochiaro, P. A., Brown, D. M., Awh, C. C., Lee, S. Y., Gray, S., Saroj, N., et al. (2011). Sustained Benefits From Ranibizumab for Macular Edema Following Central Retinal Vein Occlusion: Twelve-Month Outcomes of a Phase III Study. Ophthalmology 118 (10), 2041-2049. doi:10.1016/j.ophtha.2011.02.038

Campochiaro, P. A., Brown, D. M., Pearson, A., Chen, S., Boyer, D., Ruiz-Moreno, J., et al. (2012). Sustained Delivery Fluocinolone Acetonide Vitreous Inserts Provide Benefit for at Least 3 Years in Patients with Diabetic Macular Edema. Ophthalmology 119 (10), 2125-2132. doi:10.1016/j.ophtha.2012.04.030

Campochiaro, P. A., Heier, J. S., Feiner, L., Gray, S., Saroj, N., Rundle, A. C., et al. (2010). Ranibizumab for Macular Edema Following Branch Retinal Vein Occlusion: Six-Month Primary End Point Results of a Phase III Study. Ophthalmology 117 (6), 1102-1112.e1. doi:10.1016/j.ophtha.2010.02.021

Castro-Navarro, V., Monferrer-Adsuara, C., Navarro-Palop, C., MonteroHernández, J., and Cervera-Taulet, E. (2021). Effect of Dexamethasone
Intravitreal Implant on Visual Acuity and Foveal Photoreceptor Integrity in Macular Edema Secondary to Retinal Vascular Disease. Ophthalmologica 244 (1), 83-92. doi:10.1159/000512195

Capone, A., Jr, Singer, M. A., Dodwell, D. G., Dreyer, R. F., Oh, K. T., Roth, D. B., et al. (2014). Efficacy and Safety of Two or More Dexamethasone Intravitreal Implant Injections for Treatment of Macular Edema Related to Retinal Vein Occlusion (Shasta Study). Retina 34 (2), 342-351. doi:10.1097/IAE.0b013e318297f842

Challa, J. K., Gillies, M. C., Penfold, P. L., Gyory, J. F., Hunyor, A. B., and Billson, F. A., (1998). Exudative Macular Degeneration and Intravitreal Triamcinolone: 18 Month Follow Up. Aust. N. Z. J. Ophthalmol. 26 (4), 277-281. doi:10.1111/j. 1442-9071.1998.tb01330.x

Chang-Lin, J. E., Attar, M., Acheampong, A. A., Robinson, M. R., Whitcup, S. M., Kuppermann, B. D., et al. (2011). Pharmacokinetics and Pharmacodynamics of a Sustained-Release Dexamethasone Intravitreal Implant. Invest. Ophthalmol. Vis. Sci. 52 (1), 80-86. doi:10.1167/iovs.10-5285

Chen, C., Dubin, R., and Kim, M. C. (2014). Emerging Trends and New Developments in Regenerative Medicine: a Scientometric Update (2000 - 2014). Expert Opin. Biol. Ther. 14 (9), 1295-1317. doi:10.1517/14712598.2014.920813

Chen, C., Hu, Z., Liu, S., and Tseng, H. (2012). Emerging Trends in Regenerative Medicine: a Scientometric Analysis in CiteSpace. Expert Opin. Biol. Ther. 12 (5), 593-608. doi:10.1517/14712598.2012.674507

Chen, C. (2017). Science Mapping: A Systematic Review of the Literature. J. Data Inf. Sci. 2 (2), 1-40. doi:10.1515/jdis-2017-0006

Chung, S. T. L. (2020). Reading in the Presence of Macular Disease: a Mini-Review. Ophthalmic Physiol. Opt. 40 (2), 171-186. doi:10.1111/opo.12664

Cukras, C. A., Petrou, P., Chew, E. Y., Meyerle, C. B., and Wong, W. T. (2012). Oral Minocycline for the Treatment of Diabetic Macular Edema (DME): Results of a Phase I/II Clinical Study. Invest. Ophthalmol. Vis. Sci. 53 (7), 3865-3874. doi:10. 1167/iovs.11-9413

Cunningham, M. A., Edelman, J. L., and Kaushal, S. (2008). Intravitreal Steroids for Macular Edema: the Past, the Present, and the Future. Surv. Ophthalmol. 53 (2), 139-149. doi:10.1016/j.survophthal.2007.12.005

Daruich, A., Matet, A., Moulin, A., Kowalczuk, L., Nicolas, M., Sellam, A., et al. (2018). Mechanisms of Macular Edema: Beyond the Surface. Prog. Retin. Eye Res. 63, 20-68. doi:10.1016/j.preteyeres.2017.10.006

Distefano, L. N., Garcia-Arumi, J., Martinez-Castillo, V., and Boixadera, A. (2017). Combination of Anti-VEGF and Laser Photocoagulation for Diabetic Macular Edema: A Review. J. Ophthalmol. 2017, 2407037. doi:10.1155/2017/2407037

Engman, S. J., Edwards, A. O., and Bakri, S. J. (2011). Administration of Repeat Intravitreal Anti-VEGF Drugs by Retina Specialists in an Injection-Only Clinic for Patients with Exudative AMD: Patient Acceptance and Safety. Semin. Ophthalmol. 26 (6), 380-386. doi:10.3109/08820538.2011.622337

Fallico, M., Maugeri, A., Lotery, A., Longo, A., Bonfiglio, V., Russo, A., et al. (2021). Fluocinolone Acetonide Vitreous Insert for Chronic Diabetic Macular Oedema: a Systematic Review with Meta-Analysis of Real-World Experience. Sci. Rep. 11 (1), 4800. doi:10.1038/s41598-021-84362-y

Feltgen, N., Pielen, A., Hansen, L., Bertram, B., Agostini, H., Jaissle, G. B., et al. (2010). [Intravitreal Drug Therapy for Retinal Vein OcclusionPathophysiological Mechanisms and Routinely Used Drugs]. Klin. Monbl. Augenheilkd. 227 (9), 681-693. doi:10.1055/s-0029-1245606

Gaballa, S. A., Kompella, U. B., Elgarhy, O., Alqahtani, A. M., Pierscionek, B., Alany, R. G., et al. (2021). Corticosteroids in Ophthalmology: Drug Delivery Innovations, Pharmacology, Clinical Applications, and Future Perspectives. Drug Deliv. Transl Res. 11 (3), 866-893. doi:10.1007/s13346-020-00843-z

Gao, L., Zhou, L., Tian, C., Li, N., Shao, W., Peng, X., et al. (2019). Intravitreal Dexamethasone Implants versus Intravitreal Anti-VEGF Treatment in Treating Patients with Retinal Vein Occlusion: a Meta-Analysis. BMC Ophthalmol. 19 (1), 8. doi:10.1186/s12886-018-1016-7

Gillies, M. C., Sutter, F. K., Simpson, J. M., Larsson, J., Ali, H., and Zhu, M. (2006). Intravitreal Triamcinolone for Refractory Diabetic Macular Edema: Two-Year Results of a Double-Masked, Placebo-Controlled, Randomized Clinical Trial. Ophthalmology 113 (9), 1533-1538. doi:10.1016/j.ophtha.2006.02.065

Greenberg, P. B., Martidis, A., Rogers, A. H., Duker, J. S., and Reichel, E. (2002). Intravitreal Triamcinolone Acetonide for Macular Oedema Due to central Retinal Vein Occlusion. Br. J. Ophthalmol. 86 (2), 247-248. doi:10.1136/bjo.86.2.247

Gu, X., Xie, M., Jia, R., and Ge, S. (2021). Publication Trends of Research on Retinoblastoma during 2001-2021: A 20-Year Bibliometric Analysis. Front. Med. (Lausanne) 8, 675703. doi:10.3389/fmed.2021.675703 
Guler, A. T., Waaijer, C. J., and Palmblad, M. (2016). Scientific Workflows for Bibliometrics. Scientometrics 107, 385-398. doi:10.1007/s11192-016-1885-6

Haller, J. A., Bandello, F., Belfort, R., Blumenkranz, M. S., Gillies, M., Heier, J., et al. (2010). Randomized, Sham-Controlled Trial of Dexamethasone Intravitreal Implant in Patients with Macular Edema Due to Retinal Vein Occlusion. Ophthalmology 117 (6), 1134-1146. doi:10.1016/j.ophtha.2010.03.032

Haller, J. A., Bandello, F., Belfort, R., Blumenkranz, M. S., Gillies, M., Heier, J., et al. (2011). Dexamethasone Intravitreal Implant in Patients with Macular Edema Related to branch or central Retinal Vein Occlusion Twelve-Month Study Results. Ophthalmology 118 (12), 2453-2460. doi:10.1016/j.ophtha.2011.05.014

He, Y., Ren, X. J., Hu, B. J., Lam, W. C., and Li, X. R. (2018). A Meta-Analysis of the Effect of a Dexamethasone Intravitreal Implant versus Intravitreal Antivascular Endothelial Growth Factor Treatment for Diabetic Macular Edema. BMC Ophthalmol. 18 (1), 121. doi:10.1186/s12886-018-0779-1

Heiligenhaus, A., Bertram, B., Heinz, C., Krause, L., Pleyer, U., Roider, J., et al. (2014). [Statement of the German Ophthalmological Society, the Retina Society and the Professional Association of German Ophthalmologists for Intravitreal Treatment of Macular Edema in Uveitis: Date: 02/07/2014]. Ophthalmologe 111 (8), 740-748. doi:10.1007/s00347-014-3130-0

Holz, F. G., Roider, J., Ogura, Y., Korobelnik, J. F., Simader, C., Groetzbach, G., et al. (2013). VEGF Trap-Eye for Macular Oedema Secondary to central Retinal Vein Occlusion: 6-month Results of the Phase III GALILEO Study. Br. J. Ophthalmol. 97 (3), 278-284. doi:10.1136/bjophthalmol-2012-301504

Hykin, P., Prevost, A. T., Sivaprasad, S., Vasconcelos, J. C., Murphy, C., Kelly, J., et al. (2021). Intravitreal Ranibizumab versus Aflibercept versus Bevacizumab for Macular Oedema Due to central Retinal Vein Occlusion: the LEAVO Non-inferiority ThreeArm RCT. Health Technol. Assess. 25 (38), 1-196. doi:10.3310/hta25380

Ip, M. S., Scott, I. U., Vanveldhuisen, P. C., Oden, N. L., Blodi, B. A., Fisher, M., et al. (2009). A Randomized Trial Comparing the Efficacy and Safety of Intravitreal Triamcinolone With Observation to Treat Vision Loss Associated With Macular Edema Secondary to Central Retinal Vein Occlusion: The Standard Care vs. Corticosteroid for Retinal Vein Occlusion (SCORE) Study Report 5. Arch. Ophthalmol. 127 (9), 1101-1114. doi:10.1001/archophthalmol.2009.234

Iturralde, D., Spaide, R. F., Meyerle, C. B., Klancnik, J. M., Yannuzzi, L. A., Fisher, Y. L., et al. (2006). Intravitreal Bevacizumab (Avastin) Treatment of Macular Edema in Central Retinal Vein Occlusion: A Short-Term Study. Retina 26 (3), 279-284. doi:10.1097/00006982-200603000-00005

Jaissle, G. B., Szurman, P., and Bartz-Schmidt, K. U. (2004). Ocular Side Effects and Complications of Intravitreal Triamcinolone Acetonide Injection. Ophthalmologe 101 (2), 121-128. doi:10.1007/s00347-003-0975-Z

Jonas, J. B., Degenring, R. F., Kreissig, I., Akkoyun, I., and Kamppeter, B. A. (2005). Intraocular Pressure Elevation after Intravitreal Triamcinolone Acetonide Injection. Ophthalmology 112 (4), 593-598. doi:10.1016/j.ophtha.2004.10.042

Jonas, J. B. (2005). Intravitreal Triamcinolone Acetonide for Treatment of Intraocular Oedematous and Neovascular Diseases. Acta Ophthalmol. Scand. 83 (6), 645-663. doi:10.1111/j.1600-0420.2005.00592.x

Jonas, J. B. (2006). Intravitreal Triamcinolone Acetonide: a Change in a Paradigm. Ophthalmic Res. 38 (4), 218-245. doi:10.1159/000093796

Jonas, J. B., Kamppeter, B. A., Harder, B., Vossmerbaeumer, U., Sauder, G., and Spandau, U. H. (2006). Intravitreal Triamcinolone Acetonide for Diabetic Macular Edema: a Prospective, Randomized Study. J. Ocul. Pharmacol. Ther. 22 (3), 200-207. doi:10.1089/jop.2006.22.200

Jonas, J. B., Kreissig, I., and Degenring, R. (2003). Intraocular Pressure after Intravitreal Injection of Triamcinolone Acetonide. Br. J. Ophthalmol. 87 (1), 24-27. doi:10.1136/bjo.87.1.24

Jonas, J. B., Kreissig, I., and Degenring, R. (2005). Intravitreal Triamcinolone Acetonide for Treatment of Intraocular Proliferative, Exudative, and Neovascular Diseases. Prog. Retin. Eye Res. 24 (5), 587-611. doi:10.1016/j.preteyeres.2005.01.004

Jonas, J. B., Kreissig, I., and Degenring, R. F. (2003). Treatment of Oedematous, Proliferative and Neovascular Diseases by Intravitreal Triamcinolone Acetonide. Klin Monbl Augenheilkd 220 (6), 384-390. doi:10.1055/s-2003-40272

Jonas, J. B., Kreissig, I., Kamppeter, B., and Degenring, R. F. (2004). Intravitreal Triamcinolone Acetonide for the Treatment of Intraocular Edematous and Neovascular Diseases. Ophthalmologe 101 (2), 113-120. doi:10.1007/s00347003-0982-0

Jonas, J. B., Kreissig, I., Söfker, A., and Degenring, R. F. (2003). Intravitreal Injection of Triamcinolone for Diffuse Diabetic Macular Edema. Arch. Ophthalmol. 121 (1), 57-61. doi:10.1001/archopht.121.1.57
Jonas, J. B., and Söfker, A. (2001). Intraocular Injection of Crystalline Cortisone as Adjunctive Treatment of Diabetic Macular Edema. Am. J. Ophthalmol. 132 (3), 425-427. doi:10.1016/s0002-9394(01)01010-8

Karim, R., Sykakis, E., Lightman, S., and Fraser-Bell, S. (2013). Interventions for the Treatment of Uveitic Macular Edema: a Systematic Review and Meta-Analysis. Clin. Ophthalmol. 7, 1109-1144. doi:10.2147/OPTH.S40268

Khurana, R. N., Appa, S. N., Mccannel, C. A., Elman, M. J., Wittenberg, S. E., Parks, D. J., et al. (2014). Dexamethasone Implant Anterior Chamber Migration: Risk Factors, Complications, and Management Strategies. Ophthalmology 121 (1), 67-71. doi:10.1016/j.ophtha.2013.06.033

Kiddee, W., Trope, G. E., Sheng, L., Beltran-Agullo, L., Smith, M., Strungaru, M. H., et al. (2013). Intraocular Pressure Monitoring Post Intravitreal Steroids: A Systematic Review. Surv. Ophthalmol. 58 (4), 291-310. doi:10.1016/j. survophthal.2012.08.003

Kuppermann, B. D., Blumenkranz, M. S., Haller, J. A., Williams, G. A., Weinberg, D. V., Chou, C., et al. (2007). Randomized Controlled Study of an Intravitreous Dexamethasone Drug Delivery System in Patients With Persistent Macular Edema. Arch. Ophthalmol. 125 (3), 309-317. doi:10.1001/archopht.125.3.309

Lambiase, A., Abdolrahimzadeh, S., and Recupero, S. M., (2014). An Update on Intravitreal Implants in Use for Eye Disorders. Drugs Today (Barc) 50 (3), 239-249. doi:10.1358/dot.2014.50.3.2103755

Lang, G. E. (2012). Diabetic Macular Edema. Ophthalmologica 227 (Suppl. 1), 21-29. doi:10.1159/000337156

Lowder, C., Belfort, R., Lightman, S., Foster, C. S., Robinson, M. R., Schiffman, R. M., et al. (2011). Dexamethasone Intravitreal Implant for Noninfectious Intermediate or Posterior Uveitis. Arch. Ophthalmol. 129 (5), 545-553. doi:10.1001/archophthalmol.2010.339

Ma, D., Guan, B., Song, L., Liu, Q., Fan, Y., Zhao, L., et al. (2021). A Bibliometric Analysis of Exosomes in Cardiovascular Diseases from 2001 to 2021. Front Cardiovasc. Med. 8, 734514. doi:10.3389/fcvm.2021.734514

Mahdy, R. A. R., Saleh, M. M., and Almasalamy, S. M. (2010). Laser Photocoagulation versus Combined Laser Photocoagulation and Posterior Sub-tenon's Triamcinolone Injection for the Primary Treatment of Diffuse Diabetic Macular Edema. Cutan. Ocul. Toxicol. 29 (2), 91-97. doi:10.3109/15569521003587335

Martidis, A., Duker, J. S., Greenberg, P. B., Rogers, A. H., Puliafito, C. A., Reichel, E., et al. (2002). Intravitreal Triamcinolone for Refractory Diabetic Macular Edema. Ophthalmology 109 (5), 920-927. doi:10.1016/s0161-6420(02)00975-2

Massin, P., Audren, F., Haouchine, B., Erginay, A., Bergmann, J. F., Benosman, R., et al. (2004). Intravitreal Triamcinolone Acetonide for Diabetic Diffuse Macular Edema: Preliminary Results of a Prospective Controlled Trial. Ophthalmology 111 (2), 1-5. doi:10.1016/j.ophtha.2003.05.037

McGregor, F., Dick, A. D., and Burke, T. (2021). Achieving Quiescence with Fluocinolone Implants. Case Rep. Ophthalmol. 12 (2), 356-362. doi:10.1159/ 000513221

Melberg, N. S., and Olk, R. J. (1993). Corticosteroid-induced Ocular Hypertension in the Treatment of Aphakic or Pseudophakic Cystoid Macular Edema. Ophthalmology 100 (2), 164-167. doi:10.1016/s0161-6420(93)31675-1

Mohan, S., Chawla, G., Surya, J., and Raman, R. (2021). Intravitreal Anti-vascular Endothelial Growth Factor with and without Topical Non-steroidal Antiinflammatory in centre-involving Diabetic Macular Edema. Indian J. Ophthalmol. 69 (11), 3279-3282. doi:10.4103/ijo.IJO_1465_21

Mueller, P. S., Murali, N. S., Cha, S. S., Erwin, P. J., and Ghosh, A. K. (2006). The Effect of Online Status on the Impact Factors of General Internal Medicine Journals. Neth. J. Med. 64 (2), 39-44. https://www.njmonline.nl/getpdf.php?id=386

Nguyen, Q. D., Brown, D. M., Marcus, D. M., Boyer, D. S., Patel, S., Feiner, L., et al. (2012). Ranibizumab for Diabetic Macular Edema: Results From 2 Phase III Randomized Trials: RISE and RIDE. Ophthalmology 119 (4), 789-801. doi:10. 1016/j.ophtha.2011.12.039

Nussenblatt, R. B., Palestine, A. G., Chan, C. C., Stevens, G., Mellow, S. D., and Green, S. B. (1991). Randomized, Double-Masked Study of Cyclosporine Compared to Prednisolone in the Treatment of Endogenous Uveitis. Am. J. Ophthalmol. 112 (2), 138-146. doi:10.1016/s0002-9394(14)76692-9

Prager, F., Michels, S., Kriechbaum, K., Georgopoulos, M., Funk, M., Geitzenauer, W., et al. (2009). Intravitreal Bevacizumab (Avastin) for Macular Oedema Secondary to Retinal Vein Occlusion: 12-Month Results of a Prospective Clinical Trial. Br. J. Ophthalmol. 93 (4), 452-456. doi:10.1136/bjo.2008.141085

Rabena, M. D., Pieramici, D. J., Castellarin, A. A., Nasir, M. A., and Avery, R. L, (2007). Intravitreal Bevacizumab (Avastin) in the Treatment of Macular Edema 
Secondary to Branch Retinal Vein Occlusion. Retina 27 (4), 419-425. doi:10. 1097/IAE.0b013e318030e77e

Rittiphairoj, T., Mir, T. A., Li, T., and Virgili, G. (2020). Intravitreal Steroids for Macular Edema in Diabetes. Cochrane Database Syst. Rev. 11, CD005656. doi:10.1002/14651858.CD005656.pub3

Rogers, S., McIntosh, R. L., Cheung, N., Lim, L., Wang, J. J., Mitchell, P., et al. (2010). The Prevalence of Retinal Vein Occlusion: Pooled Data from Population Studies from the United States, Europe, Asia, and Australia. Ophthalmology 117 (2), 313-319. doi:10.1016/j.ophtha.2009.07.017

Romero-Aroca, P. (2015). Is Laser Photocoagulation Treatment Currently Useful in Diabetic Macular Edema? Med. Hypothesis Discov. Innov. Ophthalmol. 4 (1), 5-8.

Rosenfeld, P. J., Brown, D. M., Heier, J. S., Boyer, D. S., Kaiser, P. K., Chung, C. Y., et al. (2006). Ranibizumab for Neovascular Age-Related Macular Degeneration. N. Engl. J. Med. 355 (14), 1419-1431. doi:10.1056/NEJMoa054481

Rosenfeld, P. J., Fung, A. E., and Puliafito, C. A., (2005). Optical Coherence Tomography Findings After an Intravitreal Injection of Bevacizumab (Avastin) for Macular Edema From Central Retinal Vein Occlusion. Ophthalmic. Surg. Lasers Imaging 36 (4), 336-339.

Rothova, A., Suttorp-van Schulten, M. S., Frits Treffers, W., and Kijlstra, A. (1996). Causes and Frequency of Blindness in Patients with Intraocular Inflammatory Disease. Br. J. Ophthalmol. 80 (4), 332-336. doi:10.1136/bjo.80.4.332

Sacconi, R., Giuffrè, C., Corbelli, E., Borrelli, E., Querques, G., and Bandello, F. (2019). Emerging Therapies in the Management of Macular Edema: a Review. F1000Research 8, F1000 Faculty Rev-1413. doi:10.12688/f1000research. 19198.1

Saidel, M. A., Berreen, J., and Margolis, T. P. (2005). Cytomegalovirus Retinitis after Intravitreous Triamcinolone in an Immunocompetent Patient. Am. J. Ophthalmol. 140 (6), 1141-1143. doi:10.1016/j.ajo.2005.06.058

Sarao, V., Veritti, D., Boscia, F., and Lanzetta, P. (2014). Intravitreal Steroids for the Treatment of Retinal Diseases. ScientificWorldJournal 2014, 989501. doi:10. $1155 / 2014 / 989501$

Scaramuzzi, M., Querques, G., Spina, C. L., Lattanzio, R., and Bandello, F. (2015). Repeated Intravitreal Dexamethasone Implant (Ozurdex) for Diabetic Macular Edema. Retina 35 (6), 1216-1222. doi:10.1097/IAE.0000000000000443

Schmidt-Erfurth, U., Garcia-Arumi, J., Gerendas, B. S., Midena, E., Sivaprasad, S., Tadayoni, R., et al. (2019). Guidelines for the Management of Retinal Vein Occlusion by the European Society of Retina Specialists (EURETINA). Ophthalmologica 242 (3), 123-162. doi:10.1159/000502041

Scott, I. U., Ip, M. S., Vanveldhuisen, P. C., Oden, N. L., Blodi, B. A., Fisher, M., et al. (2009). A Randomized Trial Comparing the Efficacy and Safety of Intravitreal Triamcinolone With Standard Care to Treat Vision Loss Associated With Macular Edema Secondary to Branch Retinal Vein Occlusion: The Standard Care vs. Corticosteroid for Retinal Vein Occlusion (SCORE) Study Report 6. Arch. Ophthalmol. 127 (9), 1115-1128. doi:10.1001/ archophthalmol.2009.233

Shaw, L. T., Mackin, A., Shah, R., Jain, S., Jain, P., Nayak, R., et al. (2020). Risuteganib-a Novel Integrin Inhibitor for the Treatment of Non-exudative (Dry) Age-Related Macular Degeneration and Diabetic Macular Edema. Expert Opin. Investig. Drugs 29 (6), 547-554. doi:10.1080/13543784.2020.1763953

Shimura, M., Kitano, S., Muramatsu, D., Fukushima, H., Takamura, Y., Matsumoto, M., et al. (2020). Real-world Management of Treatment-Naïve Diabetic Macular Oedema: 2-year Visual Outcome Focusing on the Starting Year of Intervention from STREAT-DMO Study. Br. J. Ophthalmol. 104 (12), 1755-1761. doi:10.1136/bjophthalmol-2019-315726

Simó, R., Sundstrom, J. M., and Antonetti, D. A. (2014). Ocular Anti-VEGF Therapy for Diabetic Retinopathy: the Role of VEGF in the Pathogenesis of Diabetic Retinopathy. Diabetes care 37 (4), 893-899. doi:10.2337/dc13-2002

Smith, A. G., and Kaiser, P. K. (2014). Emerging Treatments for Wet Age-Related Macular Degeneration. Expert Opin. Emerg. Drugs 19 (1), 157-164. doi:10. $1517 / 14728214.2014 .884559$

Suckling, R. D., and Maslin, K. F. (1988). Pseudophakic Cystoid Macular Oedema and its Treatment with Local Steroids. Aust. N. Z. J. Ophthalmol. 16 (4), 353-359. doi:10.1111/j.1442-9071.1988.tb01241.x

Supuran, C. T. (2019). Agents for the Prevention and Treatment of Age-Related Macular Degeneration and Macular Edema: a Literature and Patent Review. Expert Opin. Ther. Pat 29 (10), 761-767. doi:10.1080/13543776.2019.1671353

Sutter, F. K., Simpson, J. M., and Gillies, M. C. (2004). Intravitreal Triamcinolone for Diabetic Macular Edema that Persists after Laser Treatment: Three-Month Efficacy and Safety Results of a Prospective, Randomized, Double-Masked, Placebo-Controlled Clinical Trial. Ophthalmology 111 (11), 2044-2049. doi:10.1016/j.ophtha.2004.05.025

Tan, G. S., Cheung, N., Simó, R., Cheung, G. C., and Wong, T. Y. (2017). Diabetic Macular Oedema. Lancet Diabetes Endocrinol. 5 (2), 143-155. doi:10.1016/ S2213-8587(16)30052-3

Tappeiner, C., Bae, H. S., Rothaus, K., Walscheid, K., and Heiligenhaus, A. (2021). Occurrence and Risk Factors for Macular Edema in Patients with Juvenile Idiopathic Arthritis-Associated Uveitis. J. Clin. Med. 10 (19), 4513. doi:10.3390/jcm10194513

Testi, I., and Pavesio, C. (2019). Preliminary Evaluation of YUTIQ ${ }^{\mathrm{TM}}$ (Fluocinolone Acetonide Intravitreal Implant $0.18 \mathrm{mg}$ ) in Posterior Uveitis. Ther. Deliv. 10 (10), 621-625. doi:10.4155/tde-2019-0051

Thompson, J. T., (2006). Cataract Formation and Other Complications of Intravitreal Triamcinolone for Macular Edema. Am. J. Ophthalmol. 141 (4), 629-637. doi:10.1016/j.ajo.2005.11.050

Tomkins-Netzer, O., Taylor, S. R., Bar, A., Lula, A., Yaganti, S., Talat, L., et al. (2014). Treatment With Repeat Dexamethasone Implants Results in LongTerm Disease Control in Eyes With Noninfectious Uveitis. Ophthalmology 121 (8), 1649-1654. doi:10.1016/j.ophtha.2014.02.003

Ufret-Vincenty, R. L., Singh, R. P., Lowder, C. Y., and Kaiser, P. K. (2007). Cytomegalovirus Retinitis after Fluocinolone Acetonide (Retisert) Implant. Am. J. Ophthalmol. 143 (2), 334-335. doi:10.1016/j.ajo.2006.09.020

van Eck, N. J., and Waltman, L. (2010). Software Survey: VOSviewer, a Computer Program for Bibliometric Mapping. Scientometrics 84 (2), 523-538. doi:10. 1007/s11192-009-0146-3

Welfer, D., Scharcanski, J., and Marinho, D. R. (2011). Fovea center Detection Based on the Retina Anatomy and Mathematical Morphology. Comput. Methods Programs Biomed. 104 (3), 397-409. doi:10.1016/j.cmpb.2010.07.006

Wells, J. A., Wells, J. A., Glassman, A. R., Ayala, A. R., Jampol, L. M., Aiello, L. P., et al. (2015). Aflibercept, Bevacizumab, or Ranibizumab for Diabetic Macular Edema. N. Engl. J. Med. 372 (13), 1193-1203. doi:10.1056/NEJMoa1414264

Whitcup, S. M., Cidlowski, J. A., Csaky, K. G., and Ambati, J. (2018). Pharmacology of Corticosteroids for Diabetic Macular Edema. Invest. Ophthalmol. Vis. Sci. 59 (1), 1-12. doi:10.1167/iovs.17-22259

Wingate, R. J., and Beaumont, P. E., (1999). Intravitreal Triamcinolone and Elevated Intraocular Pressure. Aust. N. Z. J. Ophthalmol. 27 (6), 431-432. doi:10.1046/j.1440-1606.1999.00238.x

Witmer, M. T., and Connolly, B. P. (2021). Cytomegalovirus Retinitis after an Intravitreal Dexamethasone Implant in an Immunocompetent Patient. Retin. cases brief Rep. 15 (6), 670-672. doi:10.1097/icb.0000000000000904

Yang, Y., Bailey, C., Loewenstein, A., and Massin, P. (2015). Intravitreal Corticosteroids in Diabetic Macular Edema: Pharmacokinetic Considerations. Retina 35 (12), 2440-2449. doi:10.1097/IAE.0000000000000726

Yau, J. W., Rogers, S. L., Kawasaki, R., Lamoureux, E. L., Kowalski, J. W., Bek, T., et al. (2012). Global Prevalence and Major Risk Factors of Diabetic Retinopathy. Diabetes care 35 (3), 556-564. doi:10.2337/dc11-1909

Yoshikawa, K., Kotake, S., Ichiishi, A., Sasamoto, Y., Kosaka, S., and Matsuda, H. (1995). Posterior Sub-tenon Injections of Repository Corticosteroids in Uveitis Patients with Cystoid Macular Edema. Jpn. J. Ophthalmol. 39 (1), 71-76.

Yoshizumi, Y., Ohara, Z., Tabuchi, H., Sumino, H., Maeda, Y., Mochizuki, H., et al. (2019). Effects of Kallidinogenase in Patients Undergoing Vitrectomy for Diabetic Macular Edema. Int. Ophthalmol. 39 (6), 1307-1313. doi:10.1007/s10792-018-0945-8

Conflict of Interest: The authors declare that the research was conducted in the absence of any commercial or financial relationships that could be construed as a potential conflict of interest.

Publisher's Note: All claims expressed in this article are solely those of the authors and do not necessarily represent those of their affiliated organizations, or those of the publisher, the editors and the reviewers. Any product that may be evaluated in this article, or claim that may be made by its manufacturer, is not guaranteed or endorsed by the publisher.

Copyright $\odot 2022$ Lin, Ren and Chen. This is an open-access article distributed under the terms of the Creative Commons Attribution License (CC BY). The use, distribution or reproduction in other forums is permitted, provided the original author(s) and the copyright owner(s) are credited and that the original publication in this journal is cited, in accordance with accepted academic practice. No use, distribution or reproduction is permitted which does not comply with these terms. 